UCRL-50016-82-2

Distribution Category UC-38

UCRL $=-50016-82-2$

DE\&2 020614

\title{
Mechanical Engineering Department Technical Abstracts
}

\author{
General Editor: R. M. Denney
}

Manuscript Date: July 1, 1982

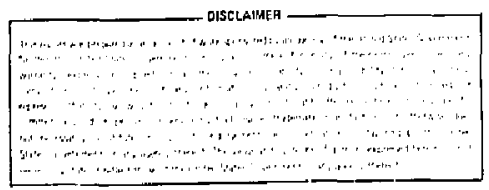

LAWRENCE LIVERMORE LABORATORY University of California • Livermore, California 94550 


\section{Preface}

The Mechanical Engineering Department publishes listings of technical abstracts twice a year to inform readers of the broad range of technical activities in the Department, and to promote an exchange of ideas. Details of the work covered by an abstract may be obtained by contacting the author(s).

Overall information about current activities of each of the Department's seven divisions precedes the technical abstracts. Specific information about technical activities may be obtained from division leaders (isted at the end of each divisional summary) or from members of the ME Technical Review Committee.

Committee members are as follows:

R.B. Carr, Deputy Department Head

E.W. McCáley, Nuclear Test Engineering Division

D.W. Ravenscroft, Nuclear Explosives Engineering Division

J.H. Pitts, Energy Systems Engineering Division

A.S. Zolnay, Weapons Engineering Division

R.H. Bossi, Engineening Sciences Division

J.D. Lee, Magnetic Fusion Engineering Division

H.H. Humpal, Materials Fabrication Divisior

R.M. Denney, General Editor. 


\section{Contents}

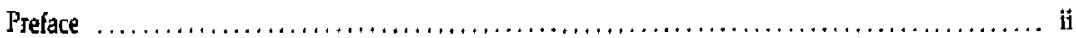

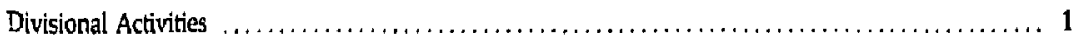

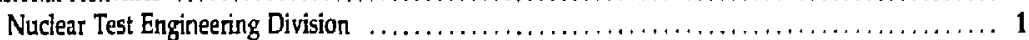

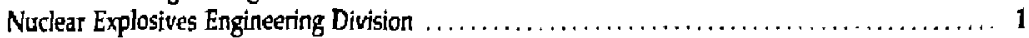

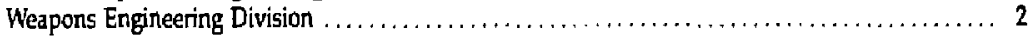

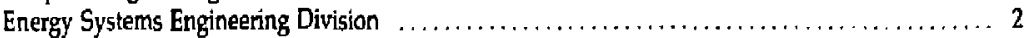

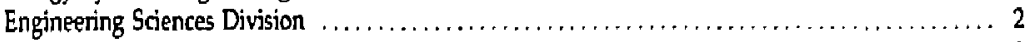

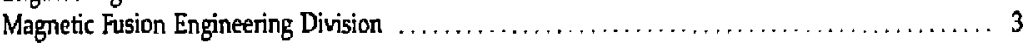

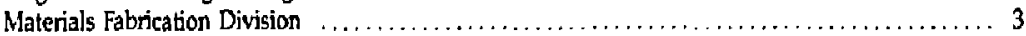

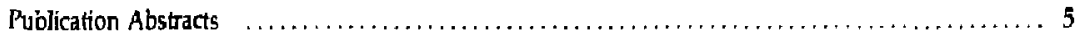




\section{Divisional Activities}

\section{Nuclear Test Engineering Division}

The Nuclear Test Engineering Divisicn (NTED) provides mecharical engineering and technical expertise for a wide range of activities in three LLNL programs: nuclear test, nuclear systems safety, and energy.

\section{Nuclear Test Program}

Our nuclear testing responsibilities involve design, structural evaluation, fabrication, and proof testing of diagnostic and device canisters that position radiation detectors and protect nuclear explosives in an underground environment. We synthesize, procure, and certify the arming and firing systems, and we develop downhole and containment systems to meet zerodetectable radioactivity release requirements. Our advanced development projects include studies of new engineering concepts, analytical and design methods, and diagnostic techniques. In carrying out this work, we strive to improve data quality and field operations, maximize safety, and optimize cost-effectiveness and resource utilization. Included in this programmatic support is spill effects testing under the Liquefied Gaseous Fuels Program.

\section{Nuclear Systems Safety Program}

The safety of nuclear power plants and associated facilities is the major concern of the Nuclear Regulatory Commission (NRC). We are responsible for providing technical data relating to reactor safety on which the NRC can base licensing decisions and assessment tools to protect public health and safery. Facilities in the nuclear fuel $\mathrm{cy}$ cle-processing and fabrication, reactor containment systems, interim waste storage, and spent fuel reprocessing-are considered from the viewpoint of safety and structural integrity.

Our multidisciplinary work is grouped into four categories: seismic and structural safety, reactor engineering, systems/operations, and licensing reviews. The NRC relies on the Laboratory as the primary facility for research on the seismic safety of nuclear power plants. Our multiyear Seismic Safety Margins Research Program (SSMRP), for examiple, defines the adequacy of seismic design for the safety of nuclear power plants in the U.S. Reactor engineering work involves accident anal$y$ sis and studies of thermal-hydraulic and fluidstructure interaction phenomena. Systems/ opcrations projects are concerned with risk assessment and control room design reviews. We also provide technical assistance to the NRC licensing staff on reactors operating or under construction.

In addition, our engineering mechanios expertise is applied to specific projects in other areas, including effort for the Magnetic Fusion Program, the Plant Engineering Department, $\mathrm{H}$ Division, and W Division.

\section{Energy Program}

We provide mechanical engineening support to several of the Laboratory's smaller energy projects and to a number of efforts for the Earth Sriences Department. Current work is under way in oil shale retorting, underground coal gasification, radionuclide migration, spent reactor fuel storage, and geophysics research. We are responsible for designing, building, and operating both Laboratory experiments and off-site field engineering tests.

(For further information, contact R.). Wasley, Ext. 2-9966.)

\section{Nuclear Explosives Engineering Division}

The Nuclear Explosives Engineering Divjsion's (NEED) major mission is to support the Laboratory's Nuclear Design Program (NDP). The activities include fielding nuclear devices for $\mathrm{Ne}$ vada Test Site expenditure. The division also supports the Nonnuclear Ordnance Program, Military Application Program (phase 1 and phase 2 studies), and $H$ (physics) Division. In addition, NEED performs studies and develops hardware for $Y$ program, $Z$ Division, and the Defense Nuclear Agency.

The Nuclear Explosives Engineering Divsion's project teams are dedicated to specific engineerning areas: conceptual nuclear design, strategic systems, development and production/liaison for 
nuclear devices, advanced fission and fusion systems, hydrodiagnostic development, and maintenance and upgrade of many test facilities at Site 300. The Division's applied mechanics group supports Laboratory programis with calculational expertise in solid mechanics and transport phenomena. The auxiliary systems group supports the Laboratory programs with expertise in high pressure gas technology; NEED also provides staff members for facilities used to conduct high pressute gas and liquid experiments. Certified tubing, valves, and other components or equipment are supplied for gas handling systems.

(For further information, contact R.A. Corallo, Exi. 28301).

\section{Weapons Engineering Division}

The Weapons Engineering Division (WED) is responsible for engineering activities supporting nuclear weapons development, production, and maintenance of an important portion of the national stockpile. In providing these services, the Division keeps abreast of new developments in safety and weapon control.

The activities include new weapon development, environmental testing, weapon control, initiation of systems development, engineering technology, and special materials procurement. Production work involyes communicating product definition and design intent to the DOE contractors responsible for component fabrication and assembly. In addition, active monitoring of the stockpile requires a careful effort in disassembly surveillance of stockpile weapons to ensure that design requirements have indeed been met and to monitor physical changes that may eventually limit the useful life of a weapon.

The Special Materials (SM) office in WED purchases guods and services from the DOE contractors, military commands, and other governmental agencies for all LLNL programs. This office is also responsible for coordinating Laboratory guidance on weapon development activities by the DOE contractors, purchasing special isotapes used in a variety of programs, and providing the DOE with a forecast and management plan on nuclear material usage.

(For further information, contact R.E. Clough, Ext. 2-8296.)

\section{Energy Systems Engineering Division}

This division is engaged in a variety of work to provide mechanical engineering support to the Laser (Y) Program in two major categories: Laser Isotope Separation (LIS) and Inertial Confinement Fusion (ICF). In the LIS program, coherent laser light is used to selectively photoionize atoms of a given isotope in a material containing several isotopes. The ionized atoms can then be separated and enriched using extractor/collectors. The ICF effort is directed at understanding the basic physics problems associated with imploding small fusion targets with high power lasers, and at developing a fusion process to provide an unlimited source of power for use during the next century. Each major category has both military and civilian applications.

(For further infurmation, contact J.E. Keller, /r. or I.R. Hauber, both at Ext. 2-7582.)

\section{Engineering Sciences Division}

The Engineering Sciences Division (ESD) provides complete lechnical services to LLNL prograns for materials characterization, engineering measurements, nondestructive evaluation, and mechanical systems design and evaluation. The Division has more than 20 separate laboratories and facilities that are organized into sections responsible for specific technological areas.

The Materials Test and Evaluation Section provides mechanical testing, such as ASTM standard tests and special tests tailored to individual customer requirements. Developments are carried out in the fields of acoustic emission, fracture mechanics, high-rate material response, experimental stress analysis, and composite materials in order to chatacterize and improve engineering designs.

The Engineering Measurements Section is engaged in work ranging from the design of a single transducer to the fielding of complate measure. ments systems. Service for the calitration and installation of transducers and accelezometers is also available.

The Nondestructive Ivaluation Section provides inspection and diagnostic testing services to LLNL programs. $X$-ray and gamma source radiography, radiation gaugirg, ultrasonics, eddy current, dye penetrant, magnetic particles, and holographic techriques are available. 
The Engineering Design Section performs design, analysis, and mechanical fabrication in support of the Chemistry and Materials Science Department and many ESD projects. The section is particularly experienced in artomated machine design, composites processing and fabrication, tritium handling, mass spectrometry, and high explosives technology.

The Life Sciences Section provides mechanical engineering support for Biomed and Environmenta! Research, Hazard's Control, and Toxic Waste Management programs. Examples of developments to meet the varied requirements of these groups include a cell sorter in Biomed, personsel dosimetry equipment in Hazards Control, and storage and/or burial containers for toxic wastes.

The LLNL Plutonium Facility is managed by the Chemistry and Materials Science Department with operational support provided in part b; ESD. The Plutonium Engineering Section in ESD provides engineering design, fabrication, and tosting services for the Facility and its users.

The Transportation Systems Research Section participates in research projects for the Depar:ment of Energy: Departi:- - $7 t$ of Transportation, and other agencies. Projects range from metal-air batteries and powered roadways to the engineering evaluation of various transpostation technologies and their impact on the nation's transportation.

(For further information, contact R.W. Werte, Ext. 2-8360.)

\section{Magnetic Fusion Engineering Division}

The Magnetic Fusion Engineering Division (MFED) supports the LLNL physics programs in four principal areas:

- Magnetic fusion energy (MFE) confinement experiments.

- MFE development and technology.

- Particle beam development.

- High energy physics.

The four areas share a common technological base, atthough their individual goals differ greatly. Each area requires support from essentially all mechanical engineering disciplines and from specialists in nomal and superconducting magnetics, cryogenic systems, vacuum systems, high-voltage components, and nucleonics.

Our role in the MFE confinement experjments is to provide systems engineering and to design and fabricate mechanical hardware. The research in magnetic mirror confinement of nuclear fusion reactions is expected to lead to uti. lizing deuterium, an isotope of hydrogen present in sea water, as a nearly inexhaustible energy source. The major confinement experiments are the Tandem Mirror Experiment (TMX), Beta II (formerly 2XIlB), and the Mirror Fusion Test Facility (MFTF).

In MFE development and terhnology, our mission is to develop the technical base and engineering skills recessary to meet future needs of magnetic confinement systems. Our active programs are the development of a multifilamentary $\mathrm{Nb}_{3} \mathrm{Sn}$ superconductor, high-vacuum technology, and fusion reactor studies. Basic research and development are emphasized to lay the groundwork for future fusion experiments.

The particle beam development program. funded by the Defense Advanced Research Projects Agency (DARPA), involves building high-current, high-voltage, electron accelerators. Such accelerators are of interest for basic physics research and in the weapons community. The present program calls for developing two accelerators, the Experimental Test Accelerator (ETA) and the Advanced Test Accelerator (ATA). The ETA program is the predecessor to the ATA, and it will generate the technology data base to build the 10-kA, 50-MieV ATA machine.

Our role in high energy physics is to provide tools with which to pursue fundamental understanding of energy and malter. Technical support is provided for experiments performed at the 100$\mathrm{MeV}$ electron linear accelerator (Linac)-three 400-keV dc high-current accelerators, a $3-\mathrm{MeV}$ electrostatic accelerator, a 6-MeV tandem electro. static accelerator, and a 76-cm cyclotron.

The MFED consists of seven project groups plus a division office.

(For further information, contact H.L. Galles, Ext. 2-8296.)

\section{Materials Fabrication Division}

The Materials Fabrication Division, a multidisciplinary organization in the Mechanical Engineering Department, provides services that are not available from commercial sources. The number and diversity of LLNL reseasch efforts make this division one of the Laboratory's largest. We 
have about 450 highly skilled persons and more than 3,700 pieces of equipment in our inventory.

With these facilities and the special capabilities of our staff we provide services in the fields of optics, welding, vacuum process, glass, plastics, sheet metal, metal finishing, metrology, pressing, inspection and assembly, as well as conventional and numerically controlled machining of metals, high explosives, and ceramics.

In-house fabrication services are available for all LLNL programs when requirements call for:

- Fabrication capabilities not readily avaiable elsewhere.
- Rapid tumaround time.

- Handling of materials that are toxic, radioactive, or classified.

In addition, the Division's facilities are used to develop improved manufacturing techniques and to advance machine tool research. Our operating philosophy is to satisfy the mechanical fabrication need of the programs, consistent with priorities set by those programs.

(For further information, contact D.K. Fisher, Exf. 2-7643.) 


\section{Publication Abstracts*}

T.W. Alger and W.J, Benett, Sealed Copper Vapor Laser Assembly, Lawrence Livermore National Laboratory, Livermore, CA, UCRL-85710 (1981). Prepared for Review of Scientific Instruments.

Improvements in a discharge heated copper vapor laser (CVI) assembly may result in greater long term performance and reliability. This new design incorporated a positive gas seal to allow high pressure sealed or controlled leak rate operation. High pressure operation at low buffer-gas leak rates results in a decrease in copper loss rate and, because of this, an improved useful lifetime. A description of materials and construction method for this copper vapor laser assembly is provided.

D.S. Baily, Y.T. lee, and R.M. More, Ab Imitio Calculation of the Charge State of Fast Heavy lon Stopped in a Finite Temperature Target, Lawrence Livermore Nationa] Laboratory, Livermore, $\mathrm{CA}$, UCRL-86393 (1981). Prepared for the 23rd Annual Meeting, American Physical Soc, Division of Plasma Physics, New York, NY, October 12-16, 1981.

As a result of recent interest in using heavy ion drivers for ICF targets, we are trying to improve our stopping power calculations. An essential part of the stopping power is a knowledge of the effective charge of the projectile, since the square of that charge state of a heavy ion stopping in a genera! target has been calculated from first principles by the use of an average atom model to integrate the rate equations. The rates of (nonMaxwellian) electron bound-bound excitation and bound-free ionization processes together with radiative recombination are included. The sub-shell splittings are represented by a quantumi-defect representation improvement of a Slater screening model. The results will be compared to the empirical Betz furmula.

C.F. Baker, C.Y. King, J.W. Lyle, R.K. Mullins, D.S. Ravenscroft, and W.M. Shay, Response of the Flash X-Ray Building at Site 300 to Explosions on Its Firing Table, Lawrence Livermore National Laboratory, Livermore, CA, UCRL-53175 (1981).

The response of the new high-explosive Flash $X$-ray Radiography Facility at Bunker 801 at LLNL

\footnotetext{
'The abstracts are arranged alphabetically by fitst author's name.
}

Site 300 to explosiuns on its firing table has heen measured. Seven charges of the high explosive $C-4$, with increasing weights of from 18 to $585 \mathrm{lb}$, were detonated. Charges were placed on a peagravel firing table on the radiographic axis if $\mathrm{ft}$ from the face of the steel bullnose protection plate. No noteworthy damage to the new building or its installed equipment occurred during these tests.

Strains on 46 strain gauges were recorded during the explosive tests. During construction of the facility, these gauges had been welded to the steel reinforcing bars in various locations, or suspended between them, and were then embedded in the structural concrete. The gauges recorded strains as high as $220 \mathrm{pin}$./in., which is equivalent to a stress of 5600 psi in steel. All elements of the structure remained well below their elastic limits, and should remain within these limits when subjected to detonations of up to $1000 \mathrm{lb}$ of TNT on the firing table.

The measured strains were less than those given by simple engineering calculations by factors of from 1.7 to 3.9. Several safety factors and conservative simplifying assumptions were included in the strain calculations, and this may account for the large differences.

Work is underway with more elabotate structurai-analysis models that use the Laboratory's large digital computers. Future experiments and computer modeling should yield better agreement between theory and experiment.

T.G. Beat, G.E. Griggs, and J.W. Dini, Quartitative Adhesion Data for Two Energetic Physical Vapor Deposition Processes, Lawrence Livermore National Laboratory, Livermore, CA, UCRL-87010 (1981). Prepared for Proc. 2nd American Electroplaters' Soc. Symp. on Plating on Difficult-to-Plate Materials, St. Louis, MO, March 25, 1982.

This paper provides quantitative ring shear adhesion data for sopper plated on titanium (Ti6A1-4V) by the hot hollow cathode physical vapor deposition process and copper plated or 304 stainless steel by magnetzon ion plating. These are the first known published data of this type for physically vapor deposited coatings and they show that adhesion on difficult to plate substrates was quite good and compares favorably with data for electrodeposited coatings on similar substrates. 
D.D. Berger, "Joining Tantalum to Alumina by Brazing," Welding Journal 60, 25 (October 1981).

A technique was needed for joining alumina to tantalum in order to provide a reliable and reproducible leaktight seal between the ends of an alumina tube and tantalum electrodes. The assemblies are for a new generation of lasers for the Laser Isotope Separation Program at the Lawrence Livermore National Laboratory. The vacuum brazing process used to make the joint is described.

D.D. Berger, Mounting a Calcium Fluoride Window, Lawrence Livermore National Laboratory, Livermore, CA, UCRL-87050 (1981). Prepared for the Review of Scientific Instruments.

A technique has been developed for joining a large calcium fuooride $\left(\mathrm{CaF}_{2}\right)$ crystal to a stainless steel flange by means of a silver transition ing. The crystal was reeded as an exit window of a Gas Scintillation Proportional Counter at LLNL.

The original objective was to develop a means of joining a $14.6 \cdot \mathrm{cm}$ diam by $1-\mathrm{cm}$ thick $(5-$ $3 / 4$ by $3 / 8$ in.) CaF, exit window to one end of a 14-cm o.d. (5-1/2 in.) $\mathrm{Al}_{2} \mathrm{O}_{3}$ tube. The following application requirements had to be considered:

1. The $\mathrm{Al}_{2} \mathrm{O}_{3}$ to $\mathrm{CaF}$, joint did not necessarily need to be vacuum tight, but it did need to contain and separate atmospheres of different high purity gases.

2. The entire system needed to be capable of being baked out at a temperature of at least $150^{\circ} \mathrm{C}$.

3. The $\mathrm{CaF}_{2}$ window had to be detachable from the $\mathrm{Al}_{2} \mathrm{O}_{3}$ tube,

4. No metal could be allowed to project into the bore of the counter.

5. Sources of contamination (e.g., elastomer 0 -rings) had to be kept to a minimum.

The approach chosen to satisfy all the above requirements consisted of attaching the $\mathrm{CaF}_{2}$ crystal to a flange which could then be bolted, and $\mathrm{O}$ ring sealed, to a mating flange that was brazed to the $\mathrm{Al}_{2} \mathrm{O}_{3}$ tube. This paper describes the technique used to join the $\mathrm{CaF}_{2}$ window by means of a silver transition ring to the flange.

A. Blake and D.D. McDaniel, Collapse of Cylindrical Fiberglass Canisters Under External Pressure, Lawrence Livermore National laboratory, Livermore, CA, UCRL-86957 (1981). Prepared for the 1982 Joint Conf, on Experimental Mechanics of the Soc. for Experimental Stress Analysis, Honolulu, HI, May 22-30, 1982.
This paper presents the results of external pressure experiments and the related strength tests for cylindrical fiberglass canisters constructed by conventional fabrication techniques. The results of the collapse tests are correlated with the theoretical predictions taking into account the actual out-of-roundness and the mechanical properties derived from tests. This investigation indicates a promising area of fiberglass canister development for external pressure and similar containment applications.

B.M. Boghosian, R.B. Campbell, and J.M. Gilmore, A Poitential Solver for Sloshing-Ion Thermol Barriers, Lawrence Ljvermore National Laboratory, Livermore, CA, UCID-19215 (1981).

The quasi-neutrality equations a! points (a) and $(b)$ in a sloshing-ion thermal barrier are derived and an algorithm for their solution is given. The solution technique is sufficiently reliable and efficient to be used in a fluid code where it must be invoked at each time step. Circumstances under which the equations admit multiple solutions are noted and discussed.

R.H. Bossi and C.T. Oien," Real-Time Radiography, Lawrence Livermore National Laboratory, Livermore, CA, UCRL-53091 (1981).

Real-time radiography is used for imaging both dynamic events and static objects. Fluortscent screens play an important role in converting radiation to light, which is then observed directly or intensified and detected. The radiographic parameters for real-time radiography are similar to conventional film radiography with special emphasis on statistics and magnification. Directviewing fluoroscopy uses the human eye as a detector of fluorescent screen light or the light from an intensifier. Remote-viewing systems replace the human observer with a television camera. The remote-viewing systems have many advantages over the direct-viewing conditions such as safety, image enhancement, and the capability to produce permanent records. This report reviews rea! time imaging system parameters and components.

"With Sandia National Laboralories, Livermore, CA. 
R.H. Bossi, A.H. Robinson, and J.P. Barton," High Frame-Rate Neutron Radiography of Dynamic Events, Lawrence Livermore National Laboratory, Livermore, CA, UCRL-86954 (1981). Prepared for the Proc. of the the World Conf. on Neutron Radiography, San Diego, CA, December 7-10, 1981.

A system has been developed to perform neutron radiographic analysis of dynamic events having a duration of several milliseconds. The system has been operated in the range of 2000 to 10,000 frames/s. Synchronization has provided high-speed-motion neutron radiographs for evaluation of the firing cycle of 7.62-mm munition rounds within a steel rifle barrel. The system has also been used to demonstrate the ability to produce neutron radiographic movies of two-phase flow.

The equinment uses the Oregon State University TRIGA reactor capable of pulsing to 3000 MW peak power, a neutron beam collimater, a srintillator neutron conversion screen coupled to an image intensifier, and a 16-mm high speed movie camera. The peak neutron flux incident at the object position is approximately $4 \times 10^{11}$ $\mathrm{n} / \mathrm{cm}^{2} \mathrm{~s}$ with a pulse, full width at half-maximum, of $9 \mathrm{~ms}$.

Special studies have been performed on the scintillator conversion screens and on the effects of statistical limitations on the image quality. Modulation transfer function analysis has been used to assist in the evaluation of the system performance.

D.M. Boyd, J.F. Shackelford, B.W. Maxfield, and G.M. Taylor, Nondestructive Evaluation of Elcctron Beam Braze loims, Lawrence Livermore National Laboratory, Livermore, CA, UCRL-87517 (1982). Prepared for Materials Evaluation, The American Society for Nondestructive Testing.

A nondestructive evaluation (NDE) program has been carried out using holographic interferometry, microradiography, and eddy current testing for the inspection of electron beam braze join:ng of dissimilar metals. Stainless steel tubing was joined to a gold-copper disk using a Cusil (copper/silver) brazing alloy. Holographic interferometry provided an indirect measure of strength by detecting the plastic deformation occurring as a result of applying a stress. Microradiography with the aid of computer graphics dis-

'Consuliant, La jolla, CA plays provided a means of measuring braze penetration into the stai iess steel tube. Correlation of results with metallographic examination and microhardness measurements shows that holography and microradiography each provide quantitative braze quality rankings. Each method correctly identified variations in braze quality independent of electron beam power (the only processing variable in sample fabrication). Eddy current results were consistent with the other NDE methods but appear to be based on variation in surface topography rather than electrical conductivity: The usefulness of the eddy current method for this problem is questionable due to its sensitivity to the small, complex test piece geometry.

D.M. Boyd and William M. Wilcox, Weld Evaluntion on Spherical Pressure Vessets Using Holographic Interferomeiry, Lawrence Livemore $\mathrm{Na}$ tional Laboratory, Livermore, CA, UCRL-84079 (1982). Prepared for Experimental Techriques, Society for Experimental Stress Analysis.

Waist welds on spherical experimental pressure vessels have been evaluated under pressure using holographic interferometry. A coincident viewing and illumination optical configuration coupled with a parabolic mirror was used so that the entire weld region could be examined with a single hologram. Positioning the pressure vessel at the focal point of the parabolic mirror provides I relatively undistorted 360 -deg view of the waist $\checkmark$ 'eld. Double exposure and real-time holography were used to obtain displacement information on the weld region. Results are compared with radiographic and ultrasonic inspections.

\section{A.E. Brown, G.E. Faulkner, and C.A. Tatro, in-} vcstigation of Acoustic Emission Response from Laser Welds II, Lawrence Livermore National Laboratory, Livermore, CA, UCRL-86928 (1981). Prepared for the 23rd AEWG Meeting, Toronto, Canada, December 1-3, 1981. Also for publication in the 1ournal of Acoustic Emission.

lnitial attempts at monitoring acoustic emission (AE) generated from laser welds indicated a comelation existed between the $\mathrm{AE}$ and the weld. Phase II of this investigation involved more sophisticated techniques in $\mathrm{AE}$ instrumentation. These techniques included windowing and categorizing the $\mathrm{AE}$ with respect to the timing of a pulsed laser system. 
A.E. Brown, C.A. Tatro, G.E. Faulkner, and S.J. Vaharriolos," Acoustic Emission Monitoring of Laser Fusion Welding, Lawrence Livermore National Laboratory, Livermore, CA, UCRL-87222 (1982). Prepared for the ASNT Spring Conf., Boston, MA. March 22-25, 1982.

As components become smaller and requirements for increased strength and reliability are increasing, laser welding is becoming the preferred method of fastening some metals. However, due to the relatively shallow depth of penetration and nanrow width of the weld bead, small changes in several parameters of the weld can dramáically affect the weld integrity.

Over the past year, a limited amount of effort has been applied to determine the effectiveness of acoustic emission techniques in in-process monitoring of laser welds.

University of California Lawrence Livermore National Laboratory (UCLLNL) contracted for feasibility studies in the application of instrumentation to monitor the acoustic emission generated during laser welding and electron beam welding. Feasibiiity was demonstrated using a $\mathrm{CO}_{2}$ laser in the pulsed mode.

UCLLNL subsequently purchased an acoustic emission system for in-process monitoring of YAG laser welds. The material of local interest was 316 stainless steel bands, 0.010 -in. thick by about 1.0 -in, wide $(0.25$ by $25 \mathrm{~mm})$. The bands were placed face to face with the edges parallel and level. A computer controlled (CNC) laser weld system was coded to pass the clamped bands through the pulsed laser beam, laying the weld bead along one eage of the bards. The laser beam width was controlled by the focal length to about 0.020 in. $(0.5 \mathrm{~mm})$. The depth of weld penetration was affected by the aperture size, height of the bands above the chill block (clamp), and laser pulse duration and energy. A standard, or "parameter", weld was to receive a 5.46 -ms pulse of laser light every $250 \mathrm{~ms}$. The bands were moved through the laser at a velocity that would permit a $70 \%$ overlap of the weld nuggets.

N.J. Brown, A Shorl Course on Optical Fabrication Technology, Lawrence Livermore National Laboratory, Livermore, CA, UCRL-86796 (1981). Prepared for the Optical Soc. of America, Annual Meeting, Orlando, FL, October 26-30, 1981.

\footnotetext{
'With Physical Arouslics Corporation, Sacramento, CA 95813 ,
}

This course covers optical shapes, the wear equation, the grinding and polishing of glass, the polishing of metals, the mechanics of polishing machines, the figuring and polishing of platellke and tubular optics, and simple shop calculations. Emphasis throughout is on numerical methods.

S.E. Bumpus, Seismic Respotse Spectrum Analysis Incorporating All Modal Mnss, Lawrence Livermore National Laboratory, Livermore, CA. Contact Nuclear Test Engineering Division for SM 81-211.

A series of codes have been assembled to perform a response spectrum analysis of a structure in accordance with procedures outlined in recent recommendations to the Nuclear Regulatory Commission. This series of codes uses the SAP4 model to obtain mode shapes and frequencies for the structure. This data is then reformatted and Iquite differently from a SAP4 response spectrum analysis) processed so that only the most significant modes are used. When the dynamic response is obtained, a file which contains the mass that did not participate in the response is also written. This mass file is then used to perform a static analysis to capture high frequency response. The dynamic and high trequency responses ase then combined in a standard SRSS manner. The inclusion of the high frequency response was previously not available but was implemented as recommended to the NRC. The MODSAP procedure for the SRSS combination of modal results was used as per the recommendations although it is now thought that CQC combination may give better results.

D. Campbell, G. Tirsell, and W. Laird, Improved 50-ps Rusipu,tse X-Fay Detector with Optical Applications, Lawrence -ivermore National Laboratory, Livermore, CA, UCRL-86340 (1981). Prepared for the 23rd Annual Meeting of the American Physical Soc, Division of Plasma Physics, New York, NY, October 12-16, 1981.

We have improved the impulse response characteristics of the LLNL. 50 ps detector significantiy. The detector has also been improved mechanically to permit much greater ease of assembly and repair. We are investigating modified versions of this design for optical applications. The detector was developed to complement the recording capability of our Thomson-CSF $4 \mathrm{GHz}$ oscilloscopes in laser-driven ICF fusion experiments research.

G.A. Carlson, W.L. Barr, B.M. Boghosian, R.S. Devoto, J.N. Doggett, G.W. Hamilton, B.M. 
Johnston, W.N. Kumai, J.D. Lee, B.G. Logan, R.W. Moir, W.S. Neef, and R.B. Campbell," Comparative Eird-Plug Study for Tandem Mirror Reactors, Lawrence Livermore National Laboratory, I.jvermore, CA, UCID-19271 (1981).

We have completed a comparative svaluation of soseral end plug configurations for tandem mirror fusion reactors with thermal barriers. The axicell configuration has been selected for further study and will be the basis for a detailed conceptual design stuay to be canried out over the next two years. The axicell end plug has a simple mirror cell produced by twa circular coils followed by a transition coil and a Yin-Yang pair, which provides for MHD stability.

D.N. Cornish, R.W. Hoard, and R. Baldi, ${ }^{\dagger}$ csign of 12-T Yim-Yang Magnets Operniting in Subcoole. Superflud Helium, Lawrence Livermore National Laboratory, Livermore, CA, UCRL-85957 (1981). Prepared for the 9th Symp, on Engineering Problems of Fusion Research, Chicago, IL, Ortober 26$29,1981$.

A conceptual design study of a large 12-T Yin-Yang pair of coils, typical of the plug coils envisioned for a tandem-mirror facility to follow MFTF, has been compleied. Because of its larger size and field s.tength, the magnetic forces are much greater than those experienced on MFTr. The main purpose of this srudy, therefore, is to assess the feasibility of such a device, paying particular attention to mechanical stress and conductor strain.

The conductor proposed operates at $15.6 \mathrm{kA}$ and conrists of a rectangular half-hard copper stabilizer with a $\mathrm{Nb}$-Ti insert in the low-field regions and $\mathrm{Nb}_{3}$, in in the high field. The coil is divided into four sections in the longitudinal direction, with steel substructure to limit the winding stress to an acceptable level. The conducter is cryostatically stabilized in superfluid $\mathrm{He}$ at $1.8 \mathrm{~K}$ and $1.2 \mathrm{~atm}$, with an operating heat flux of $0.8 \mathrm{~W} \cdot \mathrm{cm}^{-2}$.

We conclude that the building of such a mag. not system should be possible with modest extensions to present-day technologies.

Dale H. Darling, Thomas $P$. Bernat, and Brent H. Ives, Wauclength Dependence and Efficiency of Laser Heating of DT-Filled Pslymer Coated Glass Microspheres at Cryogcnic Temperatures, Lawrence

\footnotetext{
- With TRW, Inc, Redondo Beach, CA.

'With Genteral Dynamics. Convair Division, San Dicgo, CA
}

Livermore National Laboratory, Liver.nore, $\mathrm{CA}$ UCRL-86158 (1981). Prepared $f: \cdots$ the 28 th Natl. Arnerican Vacuum Suc. Symp., Anaheim, CA, November 2-6, 1981.

The ntility of using a heating laser tu raporize the solid $\mathrm{C}^{\prime} \mathrm{l}$ fill in the heat-pulse fast-refreeze method for production of uniform solid DT layers inside polymer coated glass microsphere targets, as well as the sisceptibility of such cryogenic targets to driving laser ASE depends critically on the amount of incident laser energy absorbea by the target. The relative absorption efficiency may vary witi target material (po'ymer, glass, and solid DI layers) as well as the wavelength of the illuminating laser.

We have determined experimentally the fraction of laser light incident on DT-filled cryogenic polymei coated and bare glass microsphere targets that is absorbed to produce target heating. Data has been obtained for bare glass and $\mathrm{CH}$ and CF polymer coated microspheres at 488 and 632 $\mathrm{nm}$ laser wavelengti:s.

The measurement technique used and experi . mental results obtained will be presented.

B.S. Denhoy, Vactum Systcm for Aduanced Test Accolerator, Lavrence Livermore National Laboratory. Livermore, CA, UCRL-86190 (198i), Prepared for the 28th Nationa!' Symp., American Vacuum Soc., Anaheim, CA, November 3-6, 1981.

The Advanced Teri Accelerator (ATA) is a pulsed linear electron accelerator designed to study charged particle beam propagation. The ATA is designed to produce a $10000-\mathrm{A}, 50-\mathrm{MeV}$, 70-ns elpction beam. The electron bearn acceleration is accomplished in ferrite loaded cells Each cell is capable of maintaining a $70-\mathrm{ns} 250-\mathrm{k} \mathrm{V}$ voltage pulse across a 1-in. gap.

The electron beam is contained in a 5 -in. diam, 300-ft-Jong tube. Cryopumps, turbomolecular pumps, and mechanical pumps are used to maintain a base pressure of $2 \times 10^{-6}$ Tor1 in the beam tube. The accelerator will be installed in an undergrour. tunnel. Due to the radiation environment in the tunnel, the controlling and monitoring of the vacuum equipment, pressures, and iemperatures will be done from the control room through a computer interface.

This paper describes the vacuum system design, the type of vacuum pumps specified, the reasons behind the selection of the pumps and the techniques used for conouter interfacing. 
J.W. Dini, Electrodeposition-A Viable Coating Alfernative, Lawrence Livermore National Laboratory, Livermore, CA, UCRL-87144 (1982). Prepared for the Intern. Conf, on Metallurgical Coatings and Process Techrology, San Diego, CA, Apri 4-9, 1982

This paper reviews the metals and alloys which can be produced by electrodeposition. Then, using copper as an example, the wide variation of properties that can be obtained with one metal are discussed.

J.W. Dini and H.R. Johnson, "Plating on Sorne Difficult-to-Plate Metals and Alloys," Plating and Surface Finishing 68, 64 (October 1981).

Electrodeposition of coatings on metals such as berylliurn, beryllium-copper, Kovar, magnesium, thorium, titanium, tungsten, uranium, zirconiutin, and their alloys can be problematic. This is due, in most cases, to a natural oxide surface film that readily re-forms after being removed. The plating procedures outlined in this report rely on replacing the oxide film with a displacement coating, or etshing to allow mechanical keying between the subshate and plated deposit. The effectiveness of the procedures is demonstrated by interface bond strength determined by ring-shear and conical-head tensile tests.

J.W. Dini and H.R. Johnson, Quantitative Adjesion Data for Electroless Nickel Deposited on Various Substrates, Lawrence Livermore National Laboratory, Livermore, CA, UCRL-86807 (1981). Prepared for Proc. 2nd AES Symp. on Plating on Difficult-to-Plate Materials, St. Louis, NiO, March $25,1982$.

This paper includes a review of the literature on quantitative adhesion of electroless nickel deposited on a variety of substrates. Prccedures for obtaining gord ad̉esion between electroless nickel coatings and a vatiety of aluminum alloys $(1100,2024,5083,6061$, and 7075), berylliumcopper, and 4340 steel are outlined.

J.N. Doggett, Studies for a Frision Technology Development Facility, Lawrence Livermore National Laboratory, Livermore, CA, UCRL-86972 (1982). Prepared for the Conf. on Fast, Thermil, and Fusion Reactor Exveriments, Salt Lake City, UT, April 12-15, 1982.

We have been studying small, driven fusion reactors as candidates for a Technology Development Facility (TDF) to be used for :aching reastor subsystems, components, and materials. Magnetic mirror systems are particularly interesting for this application because of their inherent steady-state operation, potertially high wall loading, and relatively small size. The stimulus for this work was the 1974 Fussion Engineering Research Facility (FERF) Study at Lawrence Livemore Nationa] Laboratory (LLNL), along with the increased emphasis on technology development in the United States National Fusion Program.

The systems so far studied have $14-\mathrm{MeV}$ neutron wall loads ranging from 1 to $3 \mathrm{MW} \cdot \mathrm{m}^{-2}$ on testing surface areas of 2 to $5 \mathrm{~m}^{2}$ with annual fluences as high as $10^{21}$ neutrans $\cdot \mathrm{cm}^{-2}$. These devices are based on physics and engineering that has been demonstrated or is scheduled for demonstration in the next year.

Our first approach was to look at a machine with a single central plasma reacting cell and two auxiliary cells, which provide improved confinement and plasma stability. This machine, with $18 \mathrm{MW}$ of fusion power, produces an average first wall flux of $1.5 \times 10^{14}$ neutrons $\cdot \mathrm{cm}^{-2} \cdot \mathrm{s}^{-1}$ over $1.8 \mathrm{~m}^{2}$ of test space, while consuming $125 \mathrm{MW}$ of utility power. İhis machine uses technology that is in hand, or to be demonstrated this year, and on tandem-mirror-barrier physics that will be demonstrated in late 1982.

The second machine we are studying is a tandem mirror machine employing str.-m stabilization like the Tandem Mirror Experinent (TMX), but with improved performance provided by the introduction of a set of unyielded, high-field, solenoid magnets to enhance plasma confirientent. This tandem version produces a fusion power of about $15 \mathrm{MW}$, yielding a uniform wall load of 0.5 $\times 10^{14}$ neutrons $\cdot \mathrm{cm}^{-2} \cdot \mathrm{s}^{-1}$ on an area of $5.5 \mathrm{~m}^{2}$ with an input power at about $250 \mathrm{MW}$.

This type of device has an excellent potential for developing and demonstrating fusion reactor technology at an early date and at minimum cost.

R.R. Donaldson, S.R. Fatterson, and D.C. Thompson, Diamond Machining and Mechanical Inspection of Optical Components, Lawrence Livermore National Laboratory, Livermore, CA, UCRL86897 (1981). Prepared for Brookhaven Conf. on Synchrotron Radiation-High Resolution Soft $X$ Ray Optics, November 18-20, 1981.

Displacement measurement and motion control are discussed for rotary and linear axes of motion, as necessary for the dimensional measurement and diamond-tool machining of grazing incidence $x$-ray optics. Examples of available performance levels are drawn from measurements 
made on current developmental hardware, and are coupled with speculation on possibie future exiensions.

\section{P.F. Durbin, G.H. Armstrong, and A. Kuramoto,} Microcomputer-Based Ultrasonic Inspection of Solder Bond's in Stuperconductirg Cable, Lawrence Liverinore National Laboratory, Livermore, CA, UCRL87598 (1982). Prepared for Materials Evaluation, journal of the American Society for Nondestructive Testing.

A real-time microcomputer-based, ultrasonic inspection system has been developed in the course of building the Mirror Fusion Icst Facility at the Lawrence Livermore National Laboratory. This inspection system is designed to evaluate solder bonding in superconducting cable before it is wound onto magnets that will help confine the fusion reaction. A five-transducer water cell and related ultrasonic equipment sends output to a high speed data ạcquisition system, and a realtime data analysis program checks the cable for flaws and aports danage to a teletypewriter. The system is designed for stand-alone operation, and will function in hassh industrial environments.

D.M. Egle, C.A. Tatro, and A.E. Brown, Frequericy Spectra of Acorstic Emission frow Nodular Cast iron, Lawrence Livermore National Laboratory, Livermore. CA, UCRL-86461. Prepared for Materials Evaluation, America. Soc. for Nondestnuctive Testing.

Experiments in determine the normalized energy spectral density of signals emanating from two different sources of acoustic emission in nodular cast iron are described. The energy spectra are computed from digitized transient acoustic emission (AE) signals and smoothed to reduce the enors caused by th. randomness of the locition of the AE source. Energy spectra of signals associated with dislocation mechanisms show significant differences compared to spectra of those caused by particulate cracking.

W.W. Feng, On Finite Deformation of Elastic and Viscoclastic Disks under Rotation, Lawrence Livermore National Lahoratory, Livermore, CA, UCRL87567 (1982). Prepared for the 2nd European Symp. on Flywheel Energy Storage, Torino, Italy. May 9-14, 1983.

'Trofesiot ol Acrospace, Mechanical and Nuclear Engineoring Lniversily' ol Oklahoma, Norman, OK.
The governing equations for a class of axisymmetric problems, under large elastic or viscoelastic defomations, are formulated in terms of two coupled first-order ordinary differential equation with explicit derivatives. This class of problems concerns a circular disk with rotational body force as well as nonuniform initial thickness. Materials with a neo-Hookean strain-energy function are used for elastic formulation. The constitutive equations developed by Christensen are used for viscoelastic formulation. A recurrent formula for the hereditary integrals is obtained. This recurrent formula makes it possible for the same gaverning equations and numerical methods to be applied to both elastic and viscoelastic problems.

W.W. Feng. On Three-Dimensional Thick Compesite Shells, Lawrence Livermore National Laboratory, Livermore, CA, UCRL-87223 (1981). Prepared for the 11th Southeastem Conf. on Theoretical and Applied Mechanics, Huntsville, Al, April 8-9. 1982.

The solutions to three-dimensional composite shells are obtained. The undeformed configurarion of the shells is assumed to have an axis of symmetry; therefore, it is governed by two independent variables. The loading can be axisymmetric or asymmetric; therefore, there are three dependent unknown functions for three components of the displacement vector. These unknown functions are determined by the minimum potential energy principle.

The results of several examples are presented in this atticle. The profile of the deformed shells and the calculated displacement vector are compared with the experimental data.

The strength of the thick composite shells is studied. The results are compared with the acous tic emissions signals from the shells during loading.

Dennis K, Fisher and James N. Doggett, $M e^{-}$ chanical Engineering Aspects of Mirror Fusion Technology, Lawrence Livermore National Laboratory, Livermore, CA, UCRL-87347 (1982). Prepared for the American Soc. of Mechanical Engineers Annual Winter Meeting, Phoenix, AZ, November 14$19,1982$.

The Mirror approach to magnetic fusion has evolved from the original simple mirror cell to today's main line efforts, the tandem mirror machine with thermal barriers. Concurrent with the physics development have been steady advances 
in the engineering technology supporting the experimental plasma physics research. As mirror fusion approaches net power production, many significant engineering challenges lie ahead.

Mitror fusion research is being pursued throughout the world. At the University of Tsukuba, Japan, the GAMMA-10 tandem mirror machine employing axisymmetric minor coils is under construction. At the Lawrence Livermore National Laboratory, the Tandem Mirror Experiment (TMX) Upgrade incorporating thermal barriers and radio frequency plasma heating has just become operational. Also at Livermore, the largest of the mirror machines, the Mirror Fusion Test Facility (MFTF), has completed successful engineering tests of its prototypical superconducting Yin-Yang ruügnet set, cryogenic, vacuum, and computer control systems. Completion of this machire, designed to achieve equivalent $Q$ 's o! 0.5 to I.O, is scheduled for 1985. Other major efforts :n the U.S. include the TARA experiment at MIT, the PHAEDRUS experiment at the University of Wisconsin, and the Symmeiric Tandem Mirror at TRW. Additional mirror fusion experiments are in various stages of design and construction in West Germany and the USSR.

The L.S, mirror program calls for the construction of several major devices on the way to commercial power. The Tandem Mirror Next Step (TMNS), slated for start of construction in the mid 1980s, will be a D-T burning device with an ignited central cell. Its principal purpose will be to demonstrate the engineering feasibility of the tandem mirror reactor. The Tandem Mirror Demonstration Reactor (TMDR), scheduled for the 19905, is conceived as a full scale reaclor which will provide data for the design and construction of reliable commercial power reactors in the 21st century. Concurrent with TMNS and TMDR is the need for the advancement of the supporting engineering technologies. The Technology Demonstration Facility (TDF), a small, driven mirror fusion reactor, is proposed as a device for developing and demonstrating reliable engineering reactor subsystems, components, and materials.

In order to achieve the programmatic milestones described, substantial advances are needed in a number of supporting engineering technologies. Several of these are specific to the mirror program. In the area of magnetics, superconducting solenoidal magnets with peak fields of up to $15 \mathrm{~T}$ over a bore of $0.5 \mathrm{~m}$ may be needed for the TMDR. Continuous duty vacuum systems capable of high rate pumping of a combination of DT and He will be required to maintain the necessary pressure conditions. In the area of plasma heating, the mirror program projects the need for high energy (approximately $200 \mathrm{keV}, 50 \mathrm{~A}$ ) continuous duty neutral bean sources, as well as high power (multimegawatt) radiu frequency plasma heating systems. Direct conversion, a technique for efficiently converting a flux of changed particles to electricity, must be further developed to handle the multimegawatt $/ \mathrm{m}^{2}$ thermal loads of reactor plasma and ion dumps. Other technological needs are generic to the fusion program. For example, safe and reliable methods for handling tritium in a reactor environment must be demonstrated, as well as techniques for remotely maintaining neutron-activated reactor components. Finally, substantial progress is needed in developing and qualifying materials for reliable use in the high fluenses of $14 \mathrm{MeV}$ neutrons characteristic of fusion reactors.

The mirror fusion program has made several orders of magnitude improvement in demonstrated performance in the past five years. We are rapidly approaching the point where engineering technology, rather than plasma physics, will become the critical path to commercial $f_{1}$ ijon power. Mechanical engineers will play key sles in the areas of magnetics, vacuum, plasma heating/fueliug, and reactor product handling systems.

D. N. Frank and N. Milleron," Automobile Flywheel Energy Storage: Practical Vacuum Requirements, Lawrence Livermore National Laboratory, Livermore, CA, UCRL-86822 (1981). Prepared for the 28th National Symp., American Vacuum Soc,, Araheim, CA, November 2-6, 1981.

For passenger automobiles with $1367 \mathrm{~kg}$ curb weight during typical driving conditions in city traffic, fuel efficiency improvements between $50-$ $100 \%(5-7 \mathrm{kJn} / \mathrm{hr})$ can be realized by proper utilization of a flywheel-energy storage unit ( $0.2 \mathrm{kWh})$ and a heat engine. $A$ brief introduction is given concerning the pros and cons of flywheels compared to other energy storage options. Discussion is then given regarding a serious concem of composite-lywheel energy storage for vihicles: that of a suitable vacuum environment for the rolating, composite flywheel. To be practical, a vacuum system for such an environment must be reliable, safe, and economical (in energy resources and dollars) to manufacture, monitor, maintain, and repair. Each embodiment of flywheel energy

'S•E*N Vac Services, 1203 Spruce St., Berkeley. CA, 94709. 
storage may be sufficiently unique to require a vacuum environment tailored to suit it. $A$ general discussion of the important vacuum parameters and practical vacuum systems is followed by examples of candidate designs.

L.L. George, Super Mann-Whitney Simulation of System Reliability, Lawrence Livermore National Laboratory, Livermore, CA, UCRL 86221. Prepared for the Winter Simulation Conf., San Diego, CA, December 6-8, 1982.

Component reliability is the probability of component survival. Companent survival can be modeled as occurring when load is less than strength. System reliability is the probability of strvival of subsets of components. A fault tree specifies which subsets are required for survival. System teliability is modeled this way in the Seismic Safety Margins Research Program.

System reliability computation is difficult because:

1. There are many components.

2. There are many subsets whose survival causes system survival.

3. Loads and strengths are dependent among themselves and on eacil other.

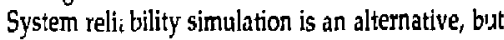
simulation requires a large number of simulation runs if component reliabilities are high. MannWhitney simulation requires far fewer simulation runs. It re-uses every one of the $\mathrm{n}^{2}$ combinations of simulated loads and strengths to estimate system reliability. Super Mann-Whitney simulation is the same as Mann-Whitney simulation except that it uses all combinations of laad-strength pairs.

For example, suppose there are $m=2 \mathrm{com}$ ponents, $n=2$ loads and strengths for esch component, and $\mathrm{n}^{2}=4$ load-strength pairs for each component. There are $n^{2 m}=16$ jairs of pairs, and each yields a distinct system state, survival or failure. Check each component to see whether its load $X$ is less than its strength $Y$, then check to see whether subsets of components required for system survival have loads less than strengths. If so, count one more survival.

The proportion of survivals in all simulation runs is a system reliability estimator. for simple simulation of $n$ independent runs with $h$ survivals, the estimator is $h / n$. For Mann-Whitney simulation of $n^{2}$ runs with i survivals, the estimator is $\mathrm{i} / \mathrm{n}^{2}$. For super Mann-Whitney simulation of $n^{2 m}$ runs with $\mathrm{j}$ survi rals, the estimator is $\mathrm{j} /\left(\mathrm{n}^{2 \mathrm{~m}}\right)$.

Every estimator should be accompanied by an indication of its accuracy. Variance of the pro- portion estimator indicates the accuracy of the system reliability estimator. For simple simulation, the variance of the proportion is estimated by $h(n-h) / n^{3}$. For Mann-Whitney simulation, the variance of the proportion is derived from the variance of the Mann-Whitney test statistic, $n^{2}(2 \pi$ $+1) / 12$ when the loads and strengths have the same distribution functions except for a location parameter For super Mann-Whitney simulation, the variance of the proportion is estimated by a jackknife estimator. The jackknife requires computing the proportion estimator n times where each computation is based on $n-1$ runs. The variance estimator is a function of the $n$ proportions.

Confidence intervals on system reliability can be estimated from the distribution function of the proportion of survivals. The exact distribution of the Mann-Whitney test statistic can be computed for small $n$. The asymptotic distribution for large $n$ is nomal. For super Mann-Whitney simulation, the distribution of the proportion depends on the definition of system survival. The distribution can be approximated using extreme value theory of depencient random variables for series or parallel systems.

R, Godwin, C. Hurley, E. Wallerstein, K. Whitman, J.E. Murray, E. Bliss, R. Ozarski, M. Summers, D. Gritton, F. Holloway, G. Suski, J. Severyn, and F. Rienecker, Engineering Design of the Novn Laser Facility for Inertial Confinement Fusion, Lawrence Livermore National Laboratory, Livermore, CA, UCRL-87444 (1981). Prepared for the th Symp. on Engineering Problems of Fusion Research, Chicago, IL, October 26-29, 1981.

The design of the Nova laser facility for inertial confinement fusion experiments at Lawrence Livermore National Laboratory is presented from an engineering perspective. Emphasis is placed upon design-to-performance requirements as they impact the various subsystems that comprise this complex experimental facility.

Alfred Goldberg, James E. Hanafee, and Robert G. Scott, Mechanical Properties Evaluation of Some Qucstionable Beryllium Material, Lawrence Livermore National Laboratory, Livermore, CA, UCRL87392 (1982). Prepared for JOWOG 22, Golden, CO, April 19-20, 1982.

We evaluated the integrity of a beryllium companent that had developed questionable etching patterns on chemical milling. The tensile properties of the questionable material, which 
was vacuum hot-pressed Be (VHP), and this material after an additional hot isostatic pressing (VHP/HIP) were compared to two (baseline) Be materials that were considered acceptable. Tensile testing was performed unoier strain-rate control conditions at $10^{-4}$ and $2 \times 10^{-2} / 5$ at $-22,22$, and $55^{\circ} \mathrm{C}$. We found that the tensile properties of all four materials fell within specifications and there were no obvious differences in their ductilities. However, differences in strer.gth values were obtained. In addition, yield drops were observed for the baseline materiais, while the VhP and VHP/HIP materials showed only a slight delay in strain hardening following initial yielding. Both the yield drop and delayed strain hardering were more pronounced with an increase in temperature.

Metailographic examination revealed that specimens of relatively low ductility showed "chevron-likr" markings llowing from a singli origin. Such markings wore virtually absent in the more ductile specimens. The lower ductility specimens were also associated with relatively larger concentrations of "fines" at crack initiation sites on the fracture suriace. As expected, segregation of mictovoids and/or inclusions was preserit in the VHT questionable material. However, fracture paths did not necessarily favor such segregated regions, a bohavior which is consistent with the absence of any significant difference in ductility between the four materials.

J. Goldhar, M.W. Taylor, and J.R. Murray, Characierization of an Efficient High Gain Roman Amplifier, Lawrence Livermore National Laboratory, Livermore, CA, UCRL-86889 (1982). Prepared for the Conf. on Lasers and Electro-Optics, Phoenix, AZ, April 14-16, 1982.

A Raman amplifier using methane gas and $\mathrm{KrF}$ laser pump was investigated. Gain, saturation characteristics, and thresholds for parasitics were experimentally measured and compared to a theoretical mode!. High conversion efficiency, pulse compression, and brightness enhancement were demonstrated

M.A. Hamstad, Acceptance Testing of Graphitie' Epoxy Composite Parts with Acoustic Emission, Lawrence Livermore National Laboratory, Livermore, CA, UCRL-86649 (19E"; Prefared for NDT International.

A graphite/epoxy composite dome is prooftested by pressurization. Aroustic emission (AE) data is obtained during tho proof test. A low- frequency bandpass is used to minimize AE signal propagation losses. The $A E$ system and test part are calibrated in situ by an instrumented pencillead break. Large energy AE signals provide a clear indication of a flawed composite part.

M.A. Hamslad, R. Wells," and A.K. Mukherjee, On the Origin of the First Peak of Acuistic Emission in 7075 Aluminum Alloy, Lawrence I ivemore National Laboratory, Livemore, CA, UCRL-86751 (1981). Prepared for the Journal of Materials Science.

The origin of acoustic emission (AE) in 7075 aluminum, alloy was investigated in tension and compression tests. It is suggested that the first peak associated with the root-mean-square (rms) $A E$ plot vs time (or strain) is due to unpinning of dislocation segments from solute atom clusters anc is not due to fraciure of particles. Alteration in the value of the AE first peak and also in electrical resistivity valu!es due to heat treatment of this alloy support the proposed origin of the $\mathrm{AE}$ first peak near yield.

Arthur R. Harvey, Amalysis and Design of Shart, Iron-Free Dipole Mngnets, Lawrence Livermore National Laboratory, livermore, CA, UCRI -86966 (1981). Prepared for the 9th Symp. on Engineering Problems of Fusion Research, Chicago, IL, October 26-29, 1981.

Iron-free, dipole magnets are used extensively as steering magnets to comect for the bending, induced by extraneous magnetic fields, of particle beams that are being transported in vacuum. Generally, the dipoles are long enough that the space occupied by the end conductors is smail compared to the overall magnet length. In a recent application, however, this criteria did not apply. This has notivated a reanalys , of the characteristies of a system of small aspect ratio (length/diameter) lipoles that are spaced at relatively large axial distances. The following observations and conclusions resulted from this analysis:

1. The effective magnet length is a simple function of the axial conductor lengths, their relative orientation, and their magnet diameter.

2. The overall magnet strength is a function of axially pasaliel conductors only

3. Fnd conductors should be placed in a single plane normal to the axis at each end of the magnet.

University of California at Davis. 
4. Flat wound and formed magnets lead to considerable cost reductions over more conventional winding methods.

5. Increasing the number of turns yields more favorable power supply matching, better field uniformity, and more lavorable heat dissipation.

6. Increasing the number of end conductors and upturing them provides a more favorable field profile at the ends of the magnet.

The above points are discussed in this report. Some fabrication techniques which are being developed in a prototype magnet are also discussed.

P. Paul Hed, Laser Rod Holder During Grinding and Polisling, Lawrence Livermore National Laboratory, Livermore, CA, UCRL-87076 (1982). Prepared for Applied Optics 21, No. 9, 1539 (1982).

The convantional way of holding a single laser rod during optical surfacing of its end faces is to cement the rod with thermoplastic material into a hole in a metal block. This method, which requires heat, is both slow and may even crack the rod. To overcome these, a clamping hoider was designed. It is made of a cylinder, a plastic bushing, and tightening screws.

R.W. Hoard, D.N. Cornish, R.W. Baldi, ${ }^{*}$ and W.D. Taylor, Uttilizing Subcooled, Stperfizid He-ll in the Design of a 12-Tesla Tandem Miror Experiment, Lawrence Livermore National Laboratary, Livermore, CA, UCRL-86326 (1981). Prepared for the Workshop on the Stability of Superconductors in He-I and He-II, Saclay, France, November 1619,1981 .

A design study of 12-T Yin-Yang coils for a conceptual Tandem Mirror Next Step (TMNS) facility has been recently performed by Lawrence Livermore National Laboratory in conjunction with the Convair Division of General Dynamics. The large magnets have major and minor radii of 3.7 and $1.5 \mathrm{~m}, 0.70 \times 3.75 \mathrm{~m}^{2}$ cross section, 46.3 $M A$ turns, and an overall current density of 1765 $\mathrm{A} / \mathrm{cm}^{2}$, obtained by the use of $\mathrm{Nb}_{3} \mathrm{Sn}$ and $\mathrm{Nb}-\mathrm{Ti}$ superconductors, Each coil is composed of several subcoils snparated by intemal strengthening sub. structure to react the enormous electromagnetic forces. The size of the Yin-Yang coils, and hence the current density, was reduced by utilizing subcooled, superfluid HE-II at $1.8 \mathrm{~K}$ for the coolant. This paper reviews the design study, with empha-

'With Ceneral Dynamics, Convair Division, Son Diego, CA 92138. sis on He-II heat transport and conductor stability. Methods are also presented which allow the extension of Gorter-Mellink-channel calculations to encompass multiple, interconnecting coolant channels.

Jack Hovingh, Performance Requirements of an Inertinl Fusion Energy Source for Hydrogen Production, Lawrence Livermore National Laboratory, Livermore, CA, UCRL-87498 (1982). Prepared for the 12th Symp. on Fusion Technology, Julich, West Gemany, September 13-17, 1982.

The production of hydrogen as a relatively nompolluting fuel for industry and transportation may be necessary in the long-term future. We are investigating the use of inertial fusion as the energy source for a hydrogen production plant.

Performance of an inertial fusion system for the production of hydrogen is compared 1, a tandem mirror system hydrogen producer. Both systems use the GA sulfur-iodine hydrogen production cycle and produce no net electric $F$ : wer to the grid. The performance parameter for the inertial fusion reactor driven hydrogen production plant is the fusion energy gain $\eta_{D} Q$ where $\eta_{D}$ is the laser efficiency and $Q$ is the pellet gain. An inertial fusion driven hydrogen producer will have a higher ratio of the heat rate of hydrogen production to the fusion reactor circulating electric power requirements than the design point for the tanderit mirror system with a fusion entergy gain of 6.9 if the inertial fusion $\eta_{0} \mathrm{Q}$ is greater than 8.8. However, for the inertial fusion to have a higher ratio of the heat rate of hydrogen production io the iusion power than the tandem mirror will require an inertial fusion 1,2 greater than 17 .

Three examples of the requirements for an inertial fusion energy source for a hydrogen production plant producing $5.8 \mathrm{~kg}$-moles $/ \mathrm{s}$ of $\mathrm{H}_{2}$ were considered. For a fusion energy gain $\eta_{D} Q$ of 8.8 and a given laser efficiency of $7 \%$, the pellet gain $Q$ required is 126 . T.1e minimum driver erergy for a "best estimate" gain of $! 26$ is 4 MJ. The pulse repetition frequency required is $11 \mathrm{~Hz}$. Reducing the laser eificiency to $4.4 \%$ will require a pellet gain of 220. The minimum driver energy for a "best estimate" gain of 220 is $10 \mathrm{MJ}$ with a prf of $2.5 \mathrm{~Hz}$. For a fusion energy gain of 17 , and a driver efficiency of $7 \%$, the required pellet gain is 240 . Using a 10-M] driver will require that the pellet performance slightly exceed the "best-estimate" gain.

An inertial fusion energy source uttlizing realistic pellet and laser performances can compete 
in terms of system performance with the tandem mirror energy source for producing hydrogen.

\section{C.A. Hurley, G. Bradley, F. Frick, C. McKee, M.} Demos, G. Lee, B. Gim, J. Braucht, A. Martos, D. Watts, and $\mathrm{H}$. Julien, ${ }^{*}$ Nova Mechanical Systems, Lawrence Livermore National Laboratory, Livermore, CA, UCRL-86008. Prepared for the 3 th Symp. on Engineering Problems of Fusion Research, Chicago, IL, October 26-29, 1981.

The mechanical subsystem of the Nova project is reponsible for the mechanical design of laser components, structural design of stable sup. ports, design of auxiljary equipment, "and their integration into the total system. A Noya beam line consists of a series of amplifier stages from $5-\mathrm{cm}$ aperture to $46-\mathrm{cm}$ aperture. In serjes with amplifiers, are spatial filters, optical isolation equipment and tuming mirrors. The output aperture of each of the 10 beams is $74 \mathrm{~cm}$.

This paper will discuss tho design features of these components, their stable support, fabrication, assembly, cooling, and operational intricacies.

The sensitivity of optical systems requires that particulate contaitination be minimized. Particles on oprical suriaces result in surface damage, when exposed to flashlamp or laser light. Consequently, in design, one must consider engineering options that do not generate contaminants. Mainraining deanliness in operation is done by rigid control of cooling gas, beam line enclosures and maintenance procedures. To ensure high system performance each feature must allow for fast, easy, clean and efficient maintenance.

To hit small targets, components and supports must be designed for high stability. Dynamic motions are limited to less than $\pm 3.0 \mu \mathrm{m}$. Thernal motion is limited by air temperature control, which is $\pm 0.5^{\circ} \mathrm{C}$ in a maximum period of 15 minutes.

Support for components is provided by the spaceframe. It is designed to be stiff, yet free to expand if thermal control is disrupted. It must withstand seismic loadings. Lenses and mimors are moulted in manipulators and gimbals that permit o.curate alignment and stability working against vacuum loads.

\footnotetext{
'Kaisur Enginetr, Oukland, CA.
}

B.C. Johnson, J.B. Bryan, M.E. Murray, M.A. Summers, J.D. Willians, and B.W. Woods, Development and Optical Performance of Large AperIure Harmonic Generation Crystal Arrays, Lawrence Livermore National Laboratory, Ljvermore, $\mathrm{CA}$, UCRL-86907 (1981). Prepared for the Conf. on Lasers and Electro-Optics, Phoenix, AZ, April 1416 (1982).

A 3-by-3 matrix of precision-oriented, diamond-machined 5-by-5-cm KDP crystals has closely matched single-crystal performance in prototyping the large-aperture arrays required for frequency convening LLNL's Nova laser.

W.K. Kelley, W.C. Cowden, and G.E. Overturf, Elcctroforming Cylindrical Parts with Precision Small Inside Diameter Pintales, Lawrence Livermore $\mathrm{Na}$ tional Laboratory, Livermore, CA, UCRL-87224 (1981). Prepared for Metals and Plastics.

The pinhole, which is the heart of the Electronic Pinex Image Neutron Expariment, is a diagnostic tool used to measure the shape of neutron emitting sources. Prior to this work there were primarily two methods for fabricating these pinholes: (1) by electrically discharge machining $(E D M)$, and (2) by conventionally drilling wafer inserts 0.125 -in, thick and stacking to the required length. We present an electroforming technique which involves plating a neutron attenuating metal onto a tube then dissolving out the tube to produce a part of the required length without stacking. Development of the electroforming process and results obtained are described in this paper.

W.K. Kelley, J.W. Dini, and C.M. Logan, "Electroforming Copper Targets for RTN5-Il," Plating and Surfact Fintishing 69, 54 (March 1982).

Copper targets used in RTNS-Il, the wrrld's most intense $14-\mathrm{MeV}$ neutron source, contain water-cooling channels for temperature control. There are two methods for fabricating these targets: (1) diffusion bonding a copper panel containing photoetched channels to another copper panel, and (2) an electroforming technique that invalves filling the photoetched channels with wax, plating thick copper to seal over the channels, and removing the wax. Development of the latter process and results obtained with it are described in this paper. 
T.A. Kozman, Y. Chang, E.N.C. Dalder, C.L. Hanson, R.E. Hinkle, J.A. Horvath, C.R. MJpntaya, D. Ng, E.O. Owen, B. Palasek, D.W. Skinner, J.H. VanSant, S.T. Wang, J.H. Berkey, R.S. Cone, R.E. Patrick, and P.N. Tirapelle, Testing of the MFTF Magnels, Lawrence Livemore Nationâi Laboratory Livermore, CA, UCRL-87506 (1982). Prepared for the 9th Intern. Cryogenic Engineering Conf., Port Island, Kobe, Japan, May 1114, 1982.

This paper describes the cooldown and testing of the first Yin-Yang magnet for the Mirror Fusion Test Facility. The introduction describes the superconducting magnet and, the rest of the paper explains the tests prior to and including magnet cooldown and iinal acceptance testing. The MFTF (originally MX) was proposed in 1976 and the project was funded for construction start in October 1977. Construction of the first large superconducting magnet set was completed in May 1981 and testing started shortly thereafter. The acceptance test procedures were reviewed in May 1981 and the cooldown and final acceptance test were done by the end of February 1982. During this acceptance testing the magnet achieved its full design current and field.

Satish V. Kulkarni and Alan J. Harnibal," Fabntcation of High Performance, Filament-Wound Composite kings, ${ }^{\dagger}$ awrence Livermore National Laboratory, Livermore, CA, UCRL-87286 (1982). Prepared for the 14th National Soc. for the Advancement of Materials and Process Engineers Technical Conf., Atlanta, GA, October 12-14. 1982.

During the past several years, many different flywheel designs made from composite materials were evaluated as potential candidates for commercial service in the future. The development of most of these concepts was funded by the Department of Energy. Of these, only two remain in the DOE program: a high energy density multi-rim design, and a modest energy density; less expensive ring-on-disk design. For the latter, the disk is a 52-glass/epoxy laminate and the ring is a carbon/epoxy circhinfsrentially wound ring. The zing is fitted over the disk by first shrinking the disk in liquid nitrogen.

This paper deals with the ring-on-disk configuration, particularly the fabrication and associ-

'With the Lord Corporation, Mechanical Group, Erie, PA. ated problems of the carbon/epoxy ring. Specifically, the following issues are presented. The winding process for rings having a thic's annular section is discussed in some detail, both for a rectangular and a tapered cross section. The purpose of the tapered cross section is to reduce the radial tensile stress. The calculated residual stresses induced by the manufacturing processes are compared with measured results. Residual stresses in the range of 7000 to 10000 psi were observed. The effect of silicone carbide whiskers on the transverse strength and transverse modulus of carbon/epoxy composites is discussed. The experimental data was measured from specimens taken from filament-wound flat panels. The impact of SiC reinforcement on the performance of a ring-on-disk flywheel is presented.

C.S. Landram, Measurement of Fusion Boundary Energy Transport During Arc Welding, Lawrence Livermore National Laboratory, Livermore, CA, UCRL-87277 1982). Prepared for the ASME lournal of Heat Transfer.

An experimentai technique is presented to identify fasion boundary (liquid/solid interface) energy transport mechanisms during welding proredures. The gas-tungsten-arc spot-welding procedure, using a low melting point specimen matesial (lead), was chosen to demonstrate the methods. Vaponzation energy losses were found to be important during the growth of the fusion boundary. Significant thermal convestion was absent within the weld pool for applied currerts less than about $100 \mathrm{~A}$, and for such cases the location of the fusion boundary was found to be govemed primarily by i zat conduction. At the current levels of almost $300 \mathrm{~A}$, significant we,d pool convection was found to exist, especially at the (inner) stagnation point, causing a deeper penetration of the fusion boundary there.

C.S. Landram, W.H. McMaster, and E.Y. Gong, Stcom Chugging Calculations with the PELE-IC Code, Lawsence Livermore National Laboratory, Livermore, CA, UCRL-86207 (1981). Prepared for the Jourmal of Nuclear Engincering Design.

Vapor region collapse mechanisms during chugging in Boiling Water Reactor (BWR) pressure suppression systems are identified by the role of condensation in locally destabilizing the vaporliquid interface in the vicinity of the submerged tube exit, Vapor collapse is shown to be furt"er hastened by complete vapor separation from the 
end of the tube, Equivalent adiabatic vapor systems are shown to exhibit stable gas-liquid interfaces and therefore have no tendencies for collapse.

J.D. Lee, Thic Fusion Breeder. Its Potential Role and Prospects, Lawrence Livermore National Laboratory, Livermore, CA, UCRL-86995 (1981). Prepared for the Proc. of the Intern. Workshop on Nuclear Energy Evolution, sponsored by the Intern. Institute for Applied System Analysis, Schloss Laxenburg, Austria, May 25-27, 1981.

The fusion breeder is a concept that utilizes $14-\mathrm{MeV}$ neutrons from $\mathrm{D}+\mathrm{T} \rightarrow \mathrm{n}(14.1 \mathrm{MeV})$ $+\alpha(3.5 \mathrm{MeV})$ fusion reactions to produce more fuel than the tritium ( $\mathrm{T}$ ) needed to sustain the fusion process. This excess fuel production capacity is used to produce fissile material ${ }^{239} \mathrm{Pu}$ or ${ }^{2} U$ ) for subsequent use in fission reactors. We are concentrating on a class of blankets we call fission suppressed. The blanket is the region surtounding the fusion plasma in which fusion neutrons iriteract to produce fuel and heat.

The fission-suppressed blanket uses nonfission reactions [mainly $(n, 2 n)$ or $\left.\left(n, n^{\prime} t\right)\right]$ to gener ate excess neutrons for the production of net fuel. This is in contrast to the fast fission class of blankets which use (n,fiss) reactions to generate excess neutrons. Fusion reactors with fast fission blankets are commonly known as fusion-ijssion hybrids because they combine fusion and fission in the same device.

J.D. Lee, R.W. Moir, W.L. Barr, R.S. Devoto, G.W. Hamilton, and W.S. Neef (all LLNL); D.H. Berwald, J.A. Maniscalco, W.D. BjorndahI, R.B. Campbell, J.K. Garner, J. Ogren, R.H. Whitley, N. Ghoniem, and $M$. Youseff (all wilh TRW, Inc., Redondo Beach, CA; K.R. Schultz, E.T. Cheng, R.L. Creedon, I. Maya, P.W. Trester, C.P.C. Wong (all with General Atomic Co., San Diego, CA); R.P. Rose, D.L. Chapin, J.W.H. Chi, and J.S. Karbowski (all with Westinghouse Electric Corp., Pittsburgh, PA; and W.R. Grimes (ORNL), Feasibility Study of Fission-Suppressed Tandem Mirror Hybrid Renctor, Lawrence Livermore National Laboratory, Livermore, CA, UCID19327 (1982).

Results of a conceptual design study of a ${ }^{233} \mathrm{U}$ producing fusion breeder consisting of a tandem mirror fusion device and two types of fissionsuppressed blankets are presented. The majority of the study was devoted to the conceptual design and evaluation of the two blankets. However, studies in the areas of fusion engineering reactor safety, fuel reprocessing, other fuel cycle issues, economics, and deployment were also perfomed.

The first blanket studied uses an inner zone of depleted lithium for tritium breeding and cooling, with an outer zone containing molten salt for fissile breeding and cooling. This concept features on-line lithium and molten-salt fuel processing. Neutrons in excess of that needed for tritium breeding are available for fissile breeding by virtue of the ${ }^{7} \mathrm{Li}\left(n, n^{\prime} t\right)$ reaction. The secorid blanket studied uses beryllium for neutron multiplication, a LiPb suspension of $\mathrm{ThO}_{2}$ for tritium and ${ }^{233} \mathrm{U}$ breeding, helium for cooling, and features aqueous (thorex) fuel reprocessing. The beryllium resource, while possibly too limited for extensive pure fusion application, will be adequate (with carefally planned industrial expansion) for the fusion breeder application because of the large support ratio; hence few fusion breeders required. Fabrication and radiation damage of beryllium remain issues to be resolved by further study and experimentation.

Molten salt reprocessing economics were compared to aqueous refrocessing (thorex). The predisted cost (levelized) for molten-salt reproressing is $\$ 1.9 / \mathrm{g}$ fissle, whereas the aqueous reprocessing cost estimate is $\$ 23 / \mathrm{g}$ fissile for thorium metal and 28 to $42 \$ / g$ fissile for $\mathrm{ThO}_{2}$. Molten salt handling and processing appear to be attractive but require more development.

The fusion driver for these fusion breeders is a 3000-MW axicell tandem mirror operating in the thermal barrier mode with 20-T barrier coils. The $\mathrm{Li}$ - and Be-based blankets are predicted to produce 4.5 and 6.6 tonnes/y of ${ }^{233} \mathrm{U}$, respectively, in addition to the tritium required to fuel the DT fusion reactions. When used as makeup to conventional light water reactors (LWRs), $15 \mathrm{GW}$ and 22 GW of electric power can be supported. Both fission-suppressed blankets are predicted to be significantly safer than fission systems by virtue of much lower radioisotope inventories and afterheat. Initial studies indicate that both blankets have very low probability of radioactivit: release,

The electricity generation cost from fusisilfission systems consisting of these fusion breeders and conventional LWRs being supplied make fuel is predicted to be $13 \%$ and $8.9 \%$ above that of an LWR fueled with mined uranium. $\mathrm{A} \$ 100 / \mathrm{kg} \mathrm{U}_{3} \mathrm{O}_{8}$ fuel cost, $3 \%$ real $\mathrm{U}_{3} \mathrm{O}_{B}$ cost escalation, and full fissile recycle in the LWR, is assumed. The electrical output from the breeders accounts for only $8 \%$ 
and $5 \%$ of total system output. The cost of bred fissile material $\left({ }^{23} \mathrm{U}\right)$, expressed as an equivalent $\mathrm{U}_{3} \mathrm{O}_{8}$ cost, was $\$ 91 / \mathrm{lb}$ for the $\mathrm{Li}$ case with moltensalt teprocessing and $\$ 76 / \mathrm{lb}$ for the beryllium case with aqueous reprocessing.

In 1982 we plan to pursue a relatively low technology hybrid which uses beryllium and thorium (or uranium) pebbles cooled by liquid lithjum with equivalent $\mathrm{U}_{3} \mathrm{O}_{8}$ costs expected to be $\$ 75 / \mathrm{lb}$ or less. At a lower level we plan to pursue a higher technology hybric which uses beryllium and molten salt with an equivalent $\mathrm{U}_{3} \mathrm{O}_{8} \operatorname{cost}$ of $\$ 60 / \mathrm{lb}$. A ${ }^{11}$-osts are in 1980 dollars. These results are based on the hybrid costing approximately 3.5 times a light water reactor for the same nuclear power. Advances which lower the cost of the fusion reactor will lower the cost of fissile material produced.

High support ratio results in attractive deployment scenarios. Only a relatively small rumber of fusion breeders are needed to support a large-scale fission economy. In a specific fusion breader/LWR deployment example, only 81 fusion breeders would be required to support the LWR nuclear capacity reguised to meet $50 \%$ of U.S electrical demand (1600-GWe nuclear) in the year 2050. If LWRs and LMFBRs are included in the fission reactor mix, only 10 fusion breeders would be required.

P.H.Y. Lee, K.G. Tirsell, G.R. Leipelt, and W.B. Baird, Mcasurement of 2-5 keV X-Rny Emission from Laser-Target Interactions by Using Fluor-MCP and CSI-XRD Delectors, Lawrence Livermore National laboratory, Livermore, CA, UCRL-86306 (1981). Prepared for the 23rd Annual Meeting of the American Physical Soc, Division of Plasma Physics, New York, NY, October 12-16, 1981.

For inertial confinement fusion plasma diagnostics, $x$-ray diode (XRD) detectors using conventional cathodes are not sensitive enough to measure $x$ rays above $-1.5 \mathrm{keV}$. However, for laser driver fusion targets, $x$ rays in the range of 2-5 keV are important because of their mobility in the target. We have successfully used fluormicrochannel plate $\left(\mathrm{MCl}^{\prime}\right)$ detectors to obtain $\mathrm{ab}$ solute $x$-ray ineasurements in the $2-5 \mathrm{keV}$ range. Recent data obtained from expeniments on the Shiva laser system are presented. In addition, designs for a variety of channels in the range using fluor-MCP and Csl-XRD's above $1.5 \mathrm{keV}$ will be discussed.
Donald R. Lesuer, Methodology for Studying Tank Track Pad Failures, Lawrence Livermore National Laboratory, Livermore, CA, UCRL-87393 (1982). Prepared for the U.S. Army Tank-Automotive Command, Troy, MI, March 29-30, 1982.

Lawrence Livermore National Laboratory in conjunction with the U.S. Army Tank-Automotive Command has developed a methodology for studying the tank track pad failure problem. Our means of studying this problem are centered around computer modeling and laboratory experiments. The computer modeling studies are based upon the finite element method and evaluate a cross section of tank track. Two models have been developed-one that studies the temperature buildup in pads, while the other studies the mechanical response of the pads to the operation of the vehicle. The models provide a key link between laboratory tests and expected field response. The laboratory tests interface with the analysis work in two different ways. The first is by providing material data input to the computer codes. The second is by evaluating the material resistance to failure given the temperature and stress levels of aperation provided by the models. ivaterial and design changes can be studied in a relatively inexperisive and straightforward manner using this methodology. This approach can also provide input on the critical ma: ial properties and their values for use in an engineering specification. We will present results for both the T142 and T156 track.

D.R. Lesuer, R.H. Cornell, and S.D. Santor, Cyclic-Stress-Strain Bcimior of Rubber, Lawrence Livermore National Laboratory, Livermore, $C A$, UCRL-86688 (1982). Prepared for the 1982 Joint Conf. on Experimental Mechanics of the Soc. for Experimental Stress Analysis, Honolulu, HI, May 22-30, 1982.

Rubber in general exhibits nonlinear viscoelastic behavior. One manifestation of this nonlinearity is a variation in the dynamic moduli with strain amplitude. However, a closer examination of the dependence of dynamic moduli on strain suggests that for engineering problems, a linear viscoelastic treatment may provide an adequate representation of the constitutive behavior of rubber, provided the moduli are evaluated at the strain range and loading frequency of interest. This presentation describes an experimental study 
into the suitability and limitations of a simple linear viscoelastic model used in several large deformation finite element computer codes. The procedure was to obtain the cyclic stress-strain behavin of a rubber suitable for use in a load bearing application and compare the results with the stress-strain response predicted by the finiteelement code NIKE2D. This code was developed at Lawrence Livermore National Laboratory to study the finite strain response of solids subjected to axisymmetric or plane strain deformation.

G.J. Linford, R.A. Haas, E.T. Marchi, W.W. Simmons, and M.A. Summers, Apodization of Large Aperlure Nown Laser Harmonic Conversion Crystal Arrays, Lawrence Livermore National Laboratory, Livermore, CA, UCRL-86906 (1982). Prepared for the Conf. on Lasers and Electro-Optics, Phoenix, AZ, April 14-16, 1982.

Experimental and theoretical investigations have resulted in the development of an effective apodizing technique for eliminating adverse diffraction effects produced by the interstitial obscurations in large-aperture $(74 \mathrm{~cm})$ Nova laser harmonic conversion crystal arrays.

B.W. Maxfield and K.D. Weglein," An Acoustic Microscope for Surfnce Characterization, Lawrence Livermore National Laboratory, Livermore, $C A$, UCRL-86767 (1981). Prepared for Proc. 1981 Ultrasonics Symp., Chicago.

Acoustic microscopy has been used recintly for nondestrutive thickness measurements of surface layers. The approach is based upon the thickness-dependence of the surface wave velocity in a layered medium. Using an acoustic material signature from a focused beam microscope as described in the literature, one can determine the sutface-wave velocity. This technique also has the potential of providing information on coating delects and surface adhesion. An experimental facility is being established at LLNL for the characterization of the relatively thick coatings that are protecting surfaces from corrosion and erosion. Thicknesses in the range of 0.01 to $0.25 \mathrm{~mm}$ require an operating trequency between 5 and 200 $\mathrm{MHz}$. An experimental system capable of operation at discrete frequencies between these limits has been constructed and initially used to obtain the acoustic material signature of aluminum on beryllium from which we deduce the surface wave velocity. This measured velocity compares favorable with calculated results.

\footnotetext{
'With Hughes Missiles Systems Group, Canoga Park, CA 9] 304 .
}

W. MçLean, C.A. Colmenares, R.L. Smith, and G.A. Somorjai, The Chemisorption of $\mathrm{CO}$ and $\mathrm{CO}$. on Gold Supported ThO, Films, Lawrençe Livermoı: National Laboratory, Livermore, CA, UCRL-86251 (1982). Prepared for the fournal of Physical Chemistry.

The chemisorption of $\mathrm{CO}$ and $\mathrm{CO}_{2}$ on goldsupported $\mathrm{ThO}_{2}$ films has been studied by $x$-ray photoelectron spectroscopy (XPS). At pressures $\sim 10^{-5} \mathrm{~Pa}$ both gases were found to adsorb molecularly at room temperature. The $\mathrm{ThO}_{2}$ films were prepared by drying and calcining a $\mathrm{Th}\left(\mathrm{NO}_{3}\right)_{4}-\mathrm{ThO}_{2}$ slurry which was painted onto a gold substrate. Films prepared in this manner were mechanically and chemicaliy stable, and were characterized by Auger electron spectroscopy (AES), XPS, $x$-ray diffraction, and scanning electron microscopy (SEM). Comparison of known and calculated stoichiometries has led us to propose a new atomic sensitivity factor (ASF) for the $\mathrm{Th}\left(4 \mathrm{f}_{7 / 2}\right)$ photoelectron peak.

W. McLean, C.A. Colmenares, R.L. Smith, and G.A. Somorjai, Electron-Spectroscopy Studies of Clean Iltoritum and Uranium Surfaces. Chemisorption and Initinl Stazes of Reaction zuith $\mathrm{O}_{2} \mathrm{CO}$, and $\mathrm{CO}_{2}$, Lawrence Livermore National Lahoratory, Livermore, CA. UCRL-86167. Prepared for Phys. Ret. B 25, No. 1 (1982).

The adsorpion of $\mathrm{O}_{2}, \mathrm{CO}$, and $\mathrm{CO}_{2}$ on the thorium (11i) crystal face and on polycrystalline $\alpha$-uraniur laas been investigated by $x$-ray photoelectron spectroscopy, Auger electron spectroscopy (A.ES), and secondary-ion mass spectroscopy (SIMS) at $300 \mathrm{~K}$. Oxygen adsorption on both metals resulted in the formation of the melal dioxide. $\mathrm{CO}$ and $\mathrm{CO}_{2}$ adsorption on Th(111) produced species derived from atomic carbon and oxygen; the presence of molecular $\mathrm{CO}$ was also detected. Only atomic carbon and oxygen were observed on uranium. Elemental depth profiles by AES and SIMS indicated that the casbon produced by the dissociation of $\mathrm{CO}$ or $\mathrm{CO}_{2}$ diffused into the bulk of the metals to form a carbide, while the oxygen remained on their surfaces as an oxide.

R.W. Mensing and L.L. George, Upper Probahility Limits on Failure Probabilitics when Paramelers are Uncerlain, Lawrence Livermore National Laboratory, Livermore, CA， UCRL-86213 (1981). Prepared for the Low Probability, High Consequence Risk Analysis Workshop. Washington, $D C$, June 15-17, 1982.

'Lawrence Burkeldy Labosatory, Berketey; $\mathrm{CA}$. 
In probability risk analysis, one important risk measure is the probability of failure of contponents and systems. If $S$ is the strength at failure of a component and $R$ is the response of a component subject to stress (due to normal c jeration, external forces such as earthquakes and winds), a component will fail if $R>S$. To represent inherent randomness, $R$ and $S$ are random variables. To measure risk, we must estimate $P(R>S)$. If the distributions of $R$ and $S$ are known, $P(R>S)$ is a deterministic value. However, the distributions of $R$ and $S$ are usually unknown so $P(R>S)$ must be esti inated. This paper derives an upper limit for $P(R>S)$ when the parameters of the distributions of $R$ and $S$ are uncertain and this uncertainty is represented by a probability distribution for the parameters. For instance, the distribution may be the samplirig distribution of parameter estimators. It may be a subjective distribution that expresses lack of knowledge about the parameters. The estimated upper limit is an upper probability limit on $P(R>S)$.

This paper detives an upper probability limit for $P[\phi(Z)<0]$ where the event $\phi(Z)<0$ is failure of a system, of(.) is the structure function of the system, $Z$ is a random vector of the form $Z=R-S$, and $R$ and $S$ are the response and strength vectors of the components in the system. The joint distribution, $G(\theta)$, of ti'e parameters, $\theta$, of the distribution of $Z$ is assumed. The method is to maximize

$P[\phi(Z)<0 ; \theta]$

subject to

$1 \geq \mathrm{G}(\theta) \geq 1-\alpha$

as a function of 0 . The constrained maximum of $P[\phi(Z)<0 ; \theta]$ is an upper $!-\alpha$ probability limit.

For a single component the probability limit for $P[\phi(Z)<O ; \theta]=P(R>S)$ is derived when only the means, $\mu_{R}$ and $\mu_{S}$ are uncertain. Optimization is not required. The derivation is extended to multiple, correlated vectors $R$ and $S$.

When more than the location parameters are uncertain, the probability limit for $P(R>S)$ is the solution to the mathematical programming problem defined above. The explicit solution is derived when $R$ and $S$ are independent normal or lognormal random variables and the unknown parameters are independent and uniformly distributed.

R.W, Mensing and L.L., George, Using Subjective Percentiles to Quantify Uncertainty and Estimate
Correlation of Fragility Functions, Lawrence Livermore National Laboratory, Livermore, $C A$, UCRL86224. Prepared for the U.5. Department of Energy Statistical Symp., Idaho Falls, ID, Oct. 13-15, 1982.

The objectives are to estimate:

1. The cdf's (fragility functions) of strengths of failures.

2. The joint cdf's of fragility function parameters.

3. The correlations between strengths at failures.

These estimates help estimate failure probabilities in the Seismic Safety Margins Research Program.

The data are subjective percentiles of fragility functions, percentiles of the percentiles, and percentiles of conditional fragility functions. They are obtained by an expert opinion questionnaire available from the authors. The cuestionnaire has a nominal fragility function representing inherent randomness and two other cdf's that are subjective confidence limits of specified size on the nominal fragility function. The experts give subjective percentiles of the three cdf's and identify the units of smength. The data for estimating correlation are the subjective percentiles of conditional fragility functions given the strength at failure of another component.

The fragility function parameters ase estimated by least squares from the percentiles of the nominal fragility function. The joint cdf of the parameters is estimated by bounding the parameters and unconditioning the bounds. The correlation is estimated by least squares from the conditional percentiles. Additional estimates of the fragility function parameters are obtained by least squares from the conditional percentiles. These additional estimates are compa:od with the other estimates to determine expert consistency.

The nominal fragility function is assumed to be a normal or lognormal cdf. Two test statistics, a sum of squared enors and a peudo likelihood ratio, indicate which edf is more likeiy. The subjec. tive confidence limit cdf's are assumed to pass through the 10th and 90th percentiles of the uncertain mean strength at failure. The conditional fragility functions are also assumed to be normal or lognormal. Therefore, the conditional percentiles are functions of correlation which allow correlation to be estimated.

The joint cdf of uncertain mean and variance is estimated as follows. Conditional on a value of the upper 90th percentile on the mean, the var:ance is bounded below by the smaller variance of 
the cdf's that pass through the 90th percentiles on the other subjective percentiles of the nominal fragility function. Conditional on a value of the lower percentile on the mean, the variance is bounded above by the larger variance of the cdf's that pass through the 10th percentiles on the other subjective percentiles on the nominal fragility function. Unconditioning according to an assumed cdf for the uncertain mean yields the joint cdf of mean and variance.

Correlations and additional estimates of the nominal mean and variance are obtained as follows. Percentiles of the conditional fragility functions are functions of the nominal mean, yariance, and correlation and of the condition. We minimize the sum of squares of the differences between the conditional percentiles and the experts' opinions as a function of nominal mean, variance, and correlation. The sum is over all experts, percentiles, and conditions.

Michael J. Murphy, An improved Design for Dynamicnlly Londed, Thrended Int erfaces, Lawrence Livermore National Laboratory, Livermore, CA, UCRL-8673y (1982). Prepared for the Symp, on Advances and Trends in Structural and Solid Mechanics, Washington, DC, October 1982.

An improved thread design for dynamically loaded, threaded interiaces is presented. Maximum stress is generally located in the thread relief region or the root of the first thread of a threaded interface under load. Consequently, a nonuniform stress distribution exists throughout the thread. The improved thread design presented in this $\mathrm{p}^{\text {- }}$ per provides for an alternate load path resulting in a uniform stress distribution and elimination of the thread roor and relief stress concentration. Whitworth and ACME type threads have been examined using hydrodynamic finite-element analysis techniques. Correlation with experimental results is good. The new thread design has been successfully implemented in the high explosive velocity augmented kinetic energy penetrator.

William S. Neef, Jr, Sown Now Itens for Tnudem Mirrur Blmukels, Lawrence Livermore Natonal Laboratory, Livermore, CA, UCRL-86793 (1981). Prepared for the 9th Symp. on Engineering Problems of Fusion Research, IEEE, Chicago, IL, October 26-29, 1981.

The Tandem Mirror Reactor, with its cylindrical central cell, has led to numerous blanket designs taking advantage of the simple geometry. Also many new applications for fusion neutrons are now being considered. To the pure fusion electricity producers and hybrids producing fissile fuel, we are adding studies of synthesic fuel producers and fission-suppressed hybrids.

The three blanket concepts prescrted are new ideas and should be considered illustrative of the breadth of Livermore's application studies. They are not meant to imply fully analyzed designs.

J.L. Opsal, Recent Developments in Diffraction The. ory and Their Effect on the Design of Ultrasonic Inspection Systems, Lawrence Livermore National Laboratory, Livermore, CA, UCRL-87099 (1981). Prepared for SPIE's 25th Aniulal Intern. Tech. Symp, and Exhibit, San Diego, CA, August 24-28, 1981.

Significant recent developments in elastic wave scattering theory are discusscd in terms of their effect on the use of ultrasonics for quantitative ?aw characterization in structural materjals. The discussion begins with an introduction on nondestruttive evaluation (NDE) describing the nced for a quantitative ultrasonics technology that includes a knowledge of the fusidamental ultrasound-flaw interaction and the ability to apply that knowledge in practice. Our present level of understanding is then illustrated using several examples of theoretical results for both direct and inverse scattering problems. Very little mathematical detail is employed in the discussion with the emphasis placed, rather, on graphically displ..ying results and showing differing effects for different scatterers. Concluding the discussion is a description of a new, sophisticated ultrasonic test instrument, an ultrasonic test bed, under construction at the Lawrence Livermore Nationai Laboratory. This facility, when completed, will allow for the testing and practical implementation of existing and emerging advancod ultrasonic concepts such as described here,

John Opsal and Allan Rosencwaig, ThermalWave Depth-Profiling: Theory, Lawrence Livermore National Laboratory, Livermore, CA, UCRL-86544 (1981). Prepared for the Jounml of Applied Plyysics.

We have developed a one-dimensional model for thermal-wave depth-profiling that pror ides expressions for the temperature at the surface of the sample and for the thermoelastic response beneath the surface. The model shows that elastic wave interference effects produce significant differences between samples with mechanically free and constrained surfaces, and that thermal-wave 
images of thermal conductivity variations are obtainable from the themoelastic signal only if the front surface is mechanically free. We have also considered the case of subsurface heating and found that for heating occurring at depths of more than a few thermal diffusion lengths, the thermoelastic signa] becomes independent of thermal conductivity variations. This has inıportant implications for thermal-wave image range and resolution.

G.D. Poe and J.L. Opsal, Application of Paranteter Estimation/System Identification to Quantitative UIIrnsonic NDE, Lawrence Livermore National Laboratory, Livermore, CA, UCRL-87098 (1981). Prepared for the DARPA/AF Review of Progress in Cuantitative NDE, Boulder, CO, August 2-7, 1981.

The use of ultrasonics for the quantitative claracterization of flaws in materials generally requires some method of extracting useful informa. tion from the srattered ultrasonic wave assuming that the time variation of the incident wave is known. We have developed a solution to this type of problem within the framework of parameter estimation and system identification. In our approach, a solution within a prescribed set of possible solutions is sought such that an $L_{2}$-norm is minimized. The form of the noim is such that it indicates a measure of similarity between the experimental observation and the possible solutions within the prescribed set. The basis of this approach and several examples will be presented.

R.H. Reiss, A Four Position Indexing Evaporation Shuffer, Lawrence Livermore National Laboratory, Livermore, CA, UCRL-87083 (1982), Prepared for Review of S. inntific Instruments.

The vacuum deposition of four different materials in one pumpdown to a thickness of 1000 $\mathrm{nm}(100 \mathrm{~A})$ each required a special fixture that would index four specific witness flats used for measurement and calibration of the deposited materials. The purpose of this note is to describe the indexing fixture.

F. Rienecker, Jr., J.E. Field, J.D. Williams, M.A. Summers, M.S. Singh, J.R. Severyn, J.F. Kane, R.A. Dickinson, and E.A. Barma,* Nova Targel Syslems, Lawrence Livemore National Labora-

Buchlel Corporation, Sarı Francisco, CA. tery, Livermore, CA, UCRL-86014. Prepared for the 9 th Symp. on Engineering Problems of Fusion Research, Chicago, IL, October 26-25, 1981.

The Nova beam focusing artangement consists of two opposing clusters, each comprising 5 (or 10) beams positioned uniformly in angle upon the surface of a $100^{\circ}$ cone whose vertex is at the target. ICF targets must be supported ir a high vacuum, and precisely located in space. The laser beams can be focused onto the target in a variecy of geometries; in addition, Jaser pulses must arrive simultaneously in time and space. The wavelength will be varied to one-5alf and one-third of the fundamental by nonlinear crystals, which must be precisely oriented with respect to the fundamental laser beam. A]l of these motions are remotely controlled and instrumented. All comporents of the system are both massive, and delicate, requiring careful fixture dosign for fabrication, testing, and hardling. Neutron activation of components infliwnres matericis selection and personnel safety considerations.

Performance of the target is diagnosed in terms of $x$-ray spectrum vs time, shape of $x$-ray source, energy absorbed reflected and scattered, and charged particles and netutions produced.

This paper describes the mechanical aspects of designs for the Nova target chamber vacums system, lens positioners, target alignmer: oplics, plasma diagnostics and integrated controls and instrumentation.

James H. Rose* and J.L. Opsal, lmersion of UlIrnsonic Scaltering Data, Lawsencr. Livermore $\mathrm{Na}$ tional Labosatory, Livermore, CA, UCRL-87006 (1981). Prepared fo: Proc DARPA/AFML Review of Quartitative NDE, Boulder, CO, 1981.

The elastic wave inverse scattering problem is examined from the point of view of the Inverse Born Approximation (IBA). We show that the IBA yields highly accurate results for the shape of complex composite voids giver sufficient scritering data. The IBA is shown to provide accurate determinations for the size and shape of simple cracks and for a composite flaw which consists of a void with a circumferential cack. The Born $A$ pproximation is also shown to provide a means for determinirg the composition of inclusions.

\footnotetext{
"With Ames Laboratory, U.S. Departr:ant of Energy, lowa State University, Ames, IA. 50011.
} 
G.M. Sanger, Some Thoughts on the Role of Electroplated Contings in Optics and Some Considerations for Their Production, Lawrence Livermore National Laboratory, Livermore, CA, UCRL-87084 (1982). Prepared for the American Electroplaters' Soc. SUR/FIN '82, San Francisco, CA, June 20-24, 1982.

New and exotic applications of optics to directed energy weapons s;stems, advanced astrophysical, and alternative energy applications, to name a few, are forcing reconsideration of the avajlable optical materials and manufacturing processes. Metal and coated metal optics of both conventional and unconventional geometry are of particular importanes in these areas due to their unique efficiency and optimal functional proper * ties. The emerging importance of these coated metal optics will be discussed, including the types and characteristics of coatings required, the optical design process and a very short survey of the more common and important applications. Also, a perspective on the optical manufacturing technologies and their implications to the characteristics of the plated coatings is given. Finally, a short survey describing the size of the potential market for coated optics in the next decade will be presented.

G.M. Sanger anó J.W. Dini, , Perspective on Electrodeposited and Electroless Nickel Coatings Used in Optical Applications, Lawrence Livermore $\mathrm{Na}$ tional Laboratory, Livermore, CA, UCRL-87058 (1982). Prepared for the American Electroplaters Soc. SUR/FIN '82, San Francisio, CA, June 20-24, 1982.

Electrodeposits of copper, gold, silver, and electroless nickel coatings are playing an ever more important role in optical techrology. Any material that can be adherently coated with these ceposits can be finished by conventional polishing or diamond turning techniques, thus greatly expanding design strategies and supporting manufacturing capability for optical surfaces. The importance of good quality coatings, e.g,, the ab. sence of surface pits, porosity, nodules, stress, and jnclusions large enough to damage the diamond tool or adversely effect conventional polishing processes are emphasized and information is presented on influence of plating defecls on optics. Recent data on the diamond tuming and polishing of other electrodeposited coatings including bright nickel, sulfamate nickel, and tin-nickel are also included.

R.G. Scott and J.C. Stone, The Effects of Design Variables on the Critical Stresses of Eye Bars Under
Load: An Evaluation by Photoelastic Modeling, Lawrence livermore National Laboratory, Livermore, CA, UCRI-85805 (1982). Prepared for the 1982 Joint Conf. on Experimental Mechanics of the Soc. for Experimental Stress Analysis, Honolulu, HI, May 22-30, 1982.

Textbooks on machine design and relevant handbooks have not approached in depth the problem of estimating the effects of major design variables on the critical stresses in the eye-barlugs used for heavy lifting. This paper reports the critical siresses determined experimentally by the photoelastic modeling of design variations of geometry and pin clearance with and without a bushing between the pin and the lug. Experimental data are compared to values developed from theoretical analysis.

A.F. Shakal and R.C. Murray, Earthquake StrongMotion Instruntentation at Lawence Livermore $\mathrm{Na}$ tional Laboratory, Lawrence Livermore National Laboratory, Livermore, CA, UCRL-53246 (1981).

A network of strong-motion accelerographs has been installed at the Lawrence Livermore National Laboratory as part of the LLNL Site Seismic Safety Program. The network has two objectives: (1) to provide quantitative information on the severity of ground shaking for the assessment of structural effects at LLNL following an earthquake, and (2) to provide data for analyses of the free-field ground motion and the causative earthquake. The network includes digital multichannel central-recording systems in Building 111 (9channel) and in Building 332 (18-channel). Independent analog accelerographs are included to provide redundancy. A multichannel system has also been installed on the spaceframe at the Laser facility. In addition to the structural instrumentation, six free-field stations are located at and near the Laboratory. The strong-motion network wi]l provide rapid indication of peak ground-motion values as well as data for detailed post-earthquike studies of ground motion and structural response.

A.B. Shapiro and R. Gressmann, Alumintm/ Cuprous Oxide Thermite, Lawrence Livermore National Laboratory, Livermore, CA, UCRL-53189 (1982).

"Thermite" is a generic name applied to a class of metal-metal oxide reactants that undergo a chemical oxidation reduction reaction with the liberation of large amounts of themal energy. If a mixfure of aluminum and cuprous oxide is ignited, the thermitic reaction 
$2 \mathrm{Al}+3 \mathrm{Cu}_{2}-\mathrm{Al}_{2} \mathrm{O}_{3}+6 \mathrm{Cu}$

will proceed at such a rapid rate (burn rate of $6 \mathrm{~cm} / \mathrm{s}$ ) and with the evolution of 50 much heat ( $580 \mathrm{cal} / \mathrm{g}$ ) that the temperature will rise to about $2570^{\circ} \mathrm{C}$.

The thermite reaction, accordingly, has been used for sabotaging or destroying military equipment, starting military fires, and welding together large sections of metal. Aluminum/cuprous oxide $\left(\mathrm{Al} / \mathrm{Cu}_{2} \mathrm{O}\right)$ thermite is discussed in this report with respect to these topics:

- Reactant powder characterization.

- Powder contaminant extraction.

- Reactant powder compaction into a consolidated pellet.

- Initiation system.

- Reaction and reaction product analysis.

C.G. Stevens, N.J. Wessman, J.E. Bowman, and W.J. Ramsey, Photolysis of Water Vnpor on Titanium/TiO, Surfaces, Lawrence Livermore $\mathrm{Na}$ tional Laboratory, Livermore, CA, UCRL-87310 (1982). Prepared for Chemicnl Physics Letters.

The photolvsis of water vapor on the surface of titanium-coated polycrystalline $\mathrm{n}-\mathrm{TiO}_{2}$ at a temperature of $380^{\circ} \mathrm{C}$ is reported. A quantum conversion efficiency for hydrogen production of 2 peicent is measured for excitation above the band gap of $\mathrm{TiO}_{2}$. The experiments demonstrate the catalytic nature of the reaction with respect to the active material and also suggest an important role played by the titanium metal in the observations.

\section{S.E. Stokowski, W.H. Lowdermilk, F.T. Marchi,} J.E. Swain, E.P. Wallerstein, and G.R. Wirtenson, Advarces in Optical Materials for Large-Apcrturc Lasers, Lawrence Livermore National Laboratory, Livermore, CA, UCRL-86656 (1981). Prepared for Electro-Optics/Laser '81, Anaheim, $C A$, November 17-19, 1981.

Lawrence Livermore National Laboratory (LLNL) is using large-aperture Nd:glass lasers to investigate the feasibility of inertial confinement fusion. In our experiments high power laser light is focused into a small $(100-500-\mu \mathrm{m})$ target containing a deuteritum-tritium furel nixture. During the short (I to 5 ns) laser pulse the fuel is compressed and heated, resulting in fusion reactions. The generation and control of the powerful laser puises for these experiments is a challenging scientific and engineering task, which requires the development of new optical materials, fabrication techniques, and coatings. With considerable co- operation and support from the optical industry, where most of the research and development and almost all the manufacturing is done, LLNL has successfully applied several new developments in these areas.

The newest version of high power lasers for fusion research is the 20-beom Nova laser, of which 10 beams are now under construction. The output aperture of Nova is $74 \mathrm{~cm}$, considerably larger than any previous system, including the 20 beam Shiva laser with its aperture of $20 \mathrm{~cm}$. Nova will generate approximately $200-300 \mathrm{~kJ}$ of energy in $3 \mathrm{~ns}$ at $1053-\mathrm{nm}$ wavelength. Using frequency conversion in a nonlinear material, it will provide $120-200 \mathrm{~kJ}$ at $527 \mathrm{~nm}$ and $100-180 \mathrm{~kJ}$ at $351 \mathrm{~nm}$ for our fusion experiments. The following statistics indicate the massiveness of the Nova projeci:

Optics for the Nova laser ( 20 beams)

2000 major optical components

40001 of laser glass

20001 of fused silica

$2 \mathrm{G}, 000 \mathrm{~L}$ of borosilicate glass

3001 of crystals

$400 \mathrm{~m}^{2}$ of optical quality surfaces

$200 \mathrm{~m}^{2}$ of optical thin film coating

$1.1 \mathrm{~m}$ maximum diameter

$380 \mathrm{~kg}$ maximum weight

$3 \times 10^{9} \mathrm{~W} / \mathrm{cm}^{2}$ at $1 \mathrm{~ns}$ average flux

$0.06 \mu \mathrm{m}$ average optical surface accuracy.

In obtaining optics for Nova, we had to consider the large scale-up in size, the high laser flux (twice as high as previous laser systems) to which they would be exposed, and the multiple wavelength operation. At the same time we had to maintain good optical quality, high laser damage resistance, and low cost. We discuss how our laser glass, mirrors, lenses, KDP crystals (the wavelength converter), and filters meet these stringent requirements placed on them.

Irving F. Stowers and George Batcheldex, Collection of Pollen and Spore Samples in the Livermore Vollcy from February 1981 to /Wly 1982, Lawrence Livermore National Laboratory, Livermore, CA, UCRL-87262 (1982). Prepared for the 6th Intern. Symp. on Contamination Control, Tokyo, Japan, September 13, 14, 16, 1982.

Pollen and spores were collected over an 18mo period in the livermore Valley of Califomia to determine their rate of infilttation into buildings with varying air handling systems. The samples

Pollen Research Assoc,; Dir, Adult Allergy Clinic, Stanford Universily, CA. 
were collected using Rotorod samplers in both an outdoor location and at six iridoor locations. The building air tiltration systems included 30,65 and 95\% ASHRA efficient filters and 99,995\% high efficientij particulate air (HEPA) filters. Up to 50 types of pollens and spores were identified and counted on a weekly schedule, then sorted and plotted to determine indoor versus outdoor concentration ratios. The general results show that indoor concentrations were approximately 0.01 of outdoor concentrations independent of filtration type or general air handling system characteristics. The one exception was a room containing HEPA filters where indoor concentrations were even lawer when compared to the conventionally filtered rooms. The indoor concentrations generally followed (were proportional to) the outdoor concentrations throughout a pollen of spore season.

R.D. Streit, Design Guidance for Fracture-Critical Components af Lanrence Livermore National Laburatory, Lawrence Livemore National Laboratory, Livermore, CA, UCRL-53254 (198').

Fracture is an important design consideration for components whose sudden and catastrophic failuse could result in a serious accident. Elements of fracture control and fracture mechanics design methods are reviewed. Design requirements, which are based on the consequences of fracture of a given component, are subsequently developed. Five categories of consequences aje defined. Category $l$ is the lowest risk, and relatively lenient design requirements are employed. Category V has the highest potential for injury, release of hazardous material, and damage. Correspondingly, the design requirements for tivese components are the most stringent. Environmental, loading, and material factors that can affect fracture safety are also discussed.

R.D. Streit, Development of a Simple Biaxial-Strain Test, lawrence Livermore National Laboratory, Livermore, CA, UCRL-87237 (1982). Prepared for the 1982 Joint Conf. on Experimental Mechanics of the Soc. for Experimental Stress Analysis, Honolulu, $\mathrm{Hl}$, May 22-30, 1982.

Materials which obey a maximum tensile stress failure criteria can fail at strains in biaxial tension which are significantly below the uniaxial failure strain. First, a failure strain envelope is developed which accounts for the degree of biaxiality and the work hardenins of the material. A material test which would account for the vari- ous states of biayiality is then proposed. By deforming a flat plate into a prescribed surface, different states of biaxial strain can be achieved. The development of such a biaxial test as a cost-effec. tive and reliable means of screening certain materials is presented. The test is compatible with most drop weight test facilities and can be used to screen materials over a wide variety of temperature and strain rates.

M.A. Summers, L.G. Seppala, F. Rienecker, D. Eimerl, and B.C. Johnson, Nova Frequency Conversion System, Lawrence Livermere National Lab oratory, Livermore, CA, UCRL-86009 (1981). Prepared for the 9th Symp. on Engineering Probems of Fusion Research, Chicago, IL, October 26-29, 1981.

Frequency conversion of Nd:glass lasers by harmonic generation is routinely used for generating intense visible and ultraviolet light. In this article, we describe our plans for implementation of hamnonic generation on the Nova laser. The basic concept, scaling to large aperture, and intepration with the alignment and diagnostic systems are discussed. In addition, the multiwavelength target focusing system is described.

S.B. Sutton, The Effect of a Two-Dimensional Obstade on the Dispersion of a Heaviet-Thas-Air Gas in an Atmospheric Boundary Layer, Lawrence Livermore National Laboratory, Livermore, CA, UCRL-53288 (1982).

The results of a combined numerical and experimental investigation of the effect of a twodimensional obstacle on the dispersion of a heavier-than-air gas in an atmospheric boundary layer are presented.

In the numerical analysis portion, the governing equations are developed and the numerical solution algorithm is discussed. Fiuid motion was governed by the two-dimensional, incompressible Navier-Stokes equations and the equations for mass conservation. The two-equation JonesLaunder turbulence model was used to provide closure of the Reynolds stresses and fluxes. Curvature correction and pressure gradient models were incorporated in the turbulence equations. An implicit algorithm, employing the ADI technique of Peaceman and Rachford was used for the parabolic equations. The elliptic pressure equation was solved using a direct matrix solution method.

In the experimental portion, a rough wall boundary layer that simulated an atmospheric surface layer flow was generated in a $21.3-\mathrm{m}$. long 
wind tunnel having a cross section of 1.18 by $1.68 \mathrm{~m}$ at the test section. Measurements were made at a free-stream velocity of $2.4 \mathrm{~m} / \mathrm{s}$ for an obstacle size of $0.076 \mathrm{~m}$. The obstacle Reynolds number was 5339 .

Profiles of the mean velocity and turbulent kinetic energy are presented for 10 longitudinal pasitions from 5 obstacle lengths upstream to 12 obstacle lengths downstream of the leading edge of the obstacle. Results of a numerical simulation of the wind tunnel measurements are given showing the effect of turbulence model changes on the numerical solution and its comparison with measurements. Concentration results are presented for numerical simulations of dispersion in an atmospheric flow at an obstacle Reynolds number of $3.36 \times 10^{6}$, showing the effect of gas density, injection source location, and turbulence model changes on the cloud formation.

Clement A. Tatro, Acoustic Emission in Nondesiructive Evituation, Lawrence Livermore National Laboratory, Livermore, CA, UCRL-87449 (1982). Srepared as a chapter for the Encyclopedia of $\mathrm{Ma}$ terials Science and Engineering (Pergamon Press).

General information concerning acoustic emission applications to nondestructive evaluation is presented. The origins of acoustic emission in solid materials are described. Observations that can be made using a piezoelectric sensor attached to the surface of a test part are discussed, as are common methods of data analysis and recording. Unique features of acoustic emission as a nondestructive evaluation method are described, along with a discussion of the advantages and disadvantages of the method.

\section{C.A. Tatro, A.E. Brown, and S.J. Vahaviolos,"} Investigalion of Acoustic Emission Response from Laser Welds, Phiase I, Lawrence Livermore National Laboratory, Livermore, CA, UCRL-86899 (1981). Prepared for the 23rd AEWG Meeting, Toronto, Canada, December 1-3, 1981; also submitted to Welding lournol.

Initial attempts to correlate acoustic emission (AE) response to the quality of a $Y \Lambda G$ pulsed laser edge weld in stainless steel will be reported. The $A E$ record will be related to a video taped reproduction of the weld surface, magnified 120 times by means of a fiber optics microscope.
M.W. Taylor, J. Goldhar, and J.R. Murray, Dylux: an instant image photographic material suitable for UW laser beam diagnost ics, Lawrence Livermore National Laboratory, Livermore, CA, UCRL8647\%. Prepared for Applied Optics 21, No. 1, (1982).

The Du Pont Corp. Photo Products Department manufactures an instant image, dry process photographic proofing material for the graphic arts indistry which we have found to be a very useful tool for beam diagnostics in experiments using UV lasers. The material, sold under the trade name Dylux, develops a continuous-tone blue dye image when exposed to radiation at wavelengths shorter than $\sim 400 \mathrm{~nm}$. The material can be rendered insensitive to further UV exposure by fixing the image with an intense exposure to visible light. The exposure required to deactivate the material is sufficiently large that unexposed material can be handled for several minutes under normal laboratory illumination without significant change in sensitivity, and the handling period can be extended to several hours if the room lighting is subdued. The material is available in paper form as Dylux 503-1 Instant Image Proof Paper and in film form as Dylux 608 Registration Master Film,

N.L. Thomas, G.R. Wirtenson, W.L. Robinson, and E.F. Wallerstein, $A$ Scamting Reflection and Transmission Photometer for Large High Power Laser Optics, Lawrence Livermore National Laboratory, Livermase, CA, UCRL-86762 (1981). Prepared for the OSA Workshop on Optical Fabrication, Anaheim, CA, December 9-11, 1981.

The Nova Laser Fusion program at Lawrence Livermoi: National Laboratory requires the use of large optics up to $109-\mathrm{cm}$ diam and $380-\mathrm{kg}$ weight. The optical coatings for these optics consist of anti-reflection, high reflector, polarizing beamsplitter, and partial transmitter coatings. The absolute reflectance, overall transmittance, and uniformity of these coatings are measured with a specialized scanning photometer.

The Nova OTR (overall transmittance/ reflectance) photometer operates at $1.064,528$, or $351 \mathrm{~nm}$ in order to closely simulate 1st, $2 \mathrm{nd}$ and

With Physical Acoustics Corportion, Sacramento, CA 95813 
3rd harmonic frequencies of the Nova fusion laser. The optic is scanned on a large $X Y$ carriage while reflectance or transmittance data is taken "on-the-fly." The system is controlled by an LSI $11 / 23$ computer which processes the data and prints out the results in hardcopy form, or stores data on a memory disk. The detectors are temperature controlled to within $\pm 0.011^{\circ} \mathrm{C}$ which aids in achieving of an absolute accuracy of $\pm 0.1 \%$ to $\pm 0.5 \%$ of full scale, depending on the operating point. The photometer is capable of scanning a large optic (1 $\mathrm{m}$ in diameter) in 20-30 min.

E.P. Wallerstein, P. Baker, N.J. Brown, J, Bryan, W.H. Lowdermilk, F.T. Marchi, LG. Seppala, S.E. Stokowski, J. Willis, W. Whisler, and J. Williams, Optical Components for the Nova Laser, Lawrence Livermore National Laboratory, Livermore, CA, UCRL-86013 (1981). Prepared for the Tth Symp. on Engineeting Problems of Fusion Research, Chicago, IL, October 26-29, 1981.

In addition :o its other characteristics, the Nova laser fusion facility may well be the largest precision optical project ever undertaken. Moreover, during the course of construction, concurrent research and development has been successfully conducted, and has resulted in significant advances in various technical areas, including manufacturing efficiency. Although assembly of the first two beams of Nova is just commencing, the optical production, including construction of the special facilities required for many of the components, has been underway for over three years, and many phases of the optical manufacturing prograin for the first 10 beams will be completed within the next two years. On the other hand, new requirements for second and third harmonic generation have created the need to initiate new research and development. This work has been accomplished through the enormous ccoperation DOE/LLNL has received from commercial industry on this project. In many cases, industry, where much of the optical component research and development and virtually all of the manufacturing is being done, has made substantial investment of its own funds in facilities, equipment, and research and development, in addition to those supplied by DOE/LLNL.

C.F. Walter, Induclive tower Transfer for Propulsion: A Stntus Report, La'vrence Livermore $\mathrm{Na}$. tional Laboratory, Livermore, CA, UCRL-87108 (1982). Prepared for the 61st Annual Transportation Research Board Meeting, National Research Council, Washington, DC, January 18-22, (1982).
Application of the concept of inductive power transfer to propulsion of uuses, automobiles, and trucks can contribute to a quality national transportation system. The concept is basically an air gap transformer which inductively couples the primary in the roadway to the secondary suspended beneath the vehicle. Power is transferred efficiently in this manner and can be used is an electric motor for propulsion. The concept originated nearly 100 years ago, but only recen!'- received attention as a means of providing quality highway transportation with little vistal and audible presence, no noxious fumes, and without dedicated use constraints. Implementation of this concept could reduce the present, nearly complete dependence of transportation on petroleum.

Current investigations include a detailed experimental program, evaluation of the impart on electrical utility generating capacity and early applications in transit. Progress has been slowed by federal government funding limitations; future progress will be impeded unless new support is lorthcoming.

C.E. Walter, M.K. Kang, and D.J. Mullenhoff, Roule Profile Anulysis to Determine Suitability of Electric Postal Delivery Vehicle, Lawrence Livermore National Laboratory, Livermore, CA, UCRL86707 (1981). Prepared fcr the 32nd IEEE Vehicular Tech. Conf., San Diego, CA, 1982.

An instrumentation system and computer program were developed that allow the U.S. Postal Service to determine which postal routes are suitable for electric delivery vehicles. The instrumentation system provides route data. The route data and electric vehicle characteristics are used in the computer program to calculate vehicle energy and power requirements for the particular route. The performance characteristics of electric vehicles are contained in an input data file to the computer p.ogram.

The instrumentation system is designed fo: use during normal mail delivery with gasolinepowered vehicles. The system is powered by the vehicle battery. Minimum operator interaction and inexpensive maintenance-free sensors are featured in the design. Route grade is determined from a pendulum measurement conected for vehicle acceleration. Acceleration is determined from a measurement of the distance traveled. The value of road grade obtained in this manner is in excellent agreement with civil survey data. The distance transducer utilizes an electro-optical sensor and a rotating disk driven by the speedometer gear to provide a resolution of $3 \mathrm{~mm}$. A 
microprocessor provides timing and data management. Data are recorded on a cassette tape.

The instrumentation system is compact and readily installed or removed in a "survey" deliv. ery vehicle. Calibration requirements are minimal. Since postal delivery routes are closed, i.e., they begin and end at the same location (elevation), the bias error in initial orientatior. of the pendulum can be reduced to zero during data reduction. After the tape is inserted by the operator at the beginning of a run, and identification information is keyed in, data are automatically recorded in 50 -s blocks. If the vehicle is not in motion during a data block period, no data are recorded for that period.

Route data un the cassette tape are reduced in subrouting CARAIN which converts the binary data to engineering plots of time, speed, acceleration, road grade, and elevation vs distance. The program CARA determines whether a specific electric vehicle can complete the route, subject to energ; and power limitations. Output plots of battery power and battery state of charge vs time are provided. If hattery power or motor torque limitathons are exceeded, this fact is noted, but otherwise disregarded, as the calculation proceeds to the end of the route or to a set minimum value of battery state of charge. Battery state of charge is determined by a first-order-system method developed at Purdue University; the results compare well with battery test data. CARA was validated by comparing performance predictions with test data obatained with electric postal delivery vehicles. Acceptance test results indicate that a useful route profile analysis system has been developed.

S.-T. Wang, Stability and Disturbance of Large DC Superconducting Magnets, Lawrence Livermore National Laboratory, Livermore, CA, UCRL-86806 (1981). Prepared for the Superconducting Magnet Cryostability Workshop for Helium I and Helium II, CEN/Saclay, France, November 16-19, 1981.

This paper will address the stability aspects of several dc superconducting magnets such as large bubble chamber magnets, detector magnets, and magnets for the Mirror Fusion Test Facility and MHD research facility. Specifically, it will cover the Argonne National Laboratory 12-foot Bubble Chamber magn'ts, the 15-Foot Bubble Chamber magnets at Fermi National Accelerator
Laboratory, the Cello thin solenoid at Saclay, the Michigan Cyclotron magnet, the MFTF-P, magnet system at Lawrence Livermore National Laboratory, the U-25B Bypass MHD magnet, and the CFFr Superconducting MHD magnet built by Argonne National Labotatory. Discussed in detail are the design constraints, the adopted stability criterion, analyses of stability and disturbance, stability simulation and heat transfer measurements, and the final results of magnet performance.

S.-T, Wang, R. Bulmer, C. Hanson, R. Hinkle, T. Kozman, D. Shimer, R. Trtro, J. VanSant, and J. Wohlwend," The Axicall MFTF-B Superconducting Magnet System, Lawtence Livermore National Laboratory, Livermore, CA, UCRL-87563 (1982). Prepared for the 9th Intern. Cryogenic Engineering Conf., Port Island, Kobe, Japan, May 1114, 1982

The Axicell MFTF-B magnet system will provide the field environment necessary for tandem mirror plasma physics investigation with thermal barriers. The performance of the device will stimulate DT to achieve energy break-even plasma conditio is. Operation will be with deuterium only. There will be 24 superconducting coils consisting of 2 sets of Yin-Yang pairs, 14 central-cell solenoids, 2 sets of axicell mirror-coil pairs, and 2 transition coils between the axicell mirror coilpairs and Yin-Yang coils. This paper describes the progress in the design and ronstruction of the MFTF-B superconducting magnet system.

I.E. Wells, L.L. George, and G.E. Cummings, Seismic Safely Margins Research Program: Phase I Final Report-Systems Annlysis (Project VII). Prepared for the U.S. Nuclear Regulatory Commission by Lawrence Livermore National Laboratory, Livermore, CA, NUREG/CR-2015, Vol. 8, UCRL53[21, Vol. 8

This document reports on the Phase I efforts of the Systems Analysis Project to devilop the tools and methods for computing the probability of radioactive release from a commercial nuclear power plant in the event of an earthquake. The

General Dynamics, Convair Division, San Diego, CA 92138. 
results of the application of these tools and methods to the Zion Nuclear Power Plant Unit 1 are giver.

R. Werner and F, Farfaletti-Casali," The Clessidn Diverlor, Lawrence Livermore National Laboratory, Livermore, CA. The Clessidra Divertor is patent pending in Italy.

The basic idea of the Clessidra Divertor is to selectivciy pump the alpha particles (the ash) in a Tokamak reactor, leaving behind for recycle the deuteron and triton fuel. This differs from "standard" divertors, which must pump all species ( $D$ 's, T's and $\alpha$ 's) where the $\alpha$-concentration of the purnped mixture is very low ( $40 \mathrm{D}$ and $40 \mathrm{~T}$ pumped for each $\alpha_{1}$ for example).

To accomplish this selective pumping the Clessidra Divertor usess to advantage two related phenomena:

1. In the generation of divertors for the next experimental power reactors like NET operating in the high edge density regime $\left(\bar{n}_{\mathrm{s}}=10^{19}\right.$ to $10^{20}$ $\mathrm{m}^{-3}$ ) there is a very high amount of recirculation of particles in the scrape-off zone and in the divertor proper.

2. Helium, as opposed to hydrogen isotopes, does not diffuse through metals and when a surface is bombarded with energetic alphas the alphas are captured in the surface at sorie depth $\delta$ with some capture efficiency $\eta_{c}$ and are retained within the material to high fluence $\left(>10^{22} \mathrm{~m}^{-2}\right)$.

Richard W. Werner and Robert G. Hickman, Producing Thermochemicol Hydrogen with the Tondem Mirror Renctor, Lawtence Livermore National Laboratory, Livermore, CA, UCRL-87592 (1982). Prepared for the Intersociety Energy Conversion Engineering Conf, Los Angeles, CA, August 8-13, 1982.

Fusion power holds the promise to supply not only electricity but also fuels to meet the balance of our energy needs. A new integrated power and breeding blanket design is described for tandem mirror reactors. The blanket incorporates features that make it suitable [a: iynthetic fuel production. In particular, it is matched to the themal and electrical power requirements of the General Atomic water-splitting process for production of hydrogen. Some improvements to the high temperature chemical process steps are described.

\footnotetext{
Mechanical engineer with the joint Rescarch Ceneer, Ispra. Italy.
}

These improvements are expected to allow production of hydrogen at about $\$ 13 / \mathrm{G}$ ) wholesale, including financing costs, capital amortization, and profit.

Richard W. Werner, Oscar H. Krikorian, Fred L. Ribe," Lloyd C. Brown, Terry R. Galloway, Myron A. Hoffman, "* Gary L Johnson, John H. Norman ${ }^{\dagger}$ Don S. Rowe, ${ }^{\dagger}$ Shiva Sitaraman,"* Gene L. Woodruff," and T.H. Zerguini," Conceptual Design Study FY 1981: Sunfuels from FusionUsing the Tandem Mirror Reactor and a Thermochemical Cycle to Produce Hydrogen, Oscar $\mathrm{H}$. Krikorian, Ed, Lawrence Livermore National Laboratory, Ljvermore, CA, UCID-19311.

Our study on synfuels is iniended to focus primarily on the engineering aspects of coupling a tandem mirnor fusion reactor (TMR) to a thermochemical cycle for the express purpose of producing hydrogen. The hydrogen is then to be used:

- As a portable fuel.

- As a feedstock to synthesize other fuels such as gasoline or methanol.

- To produce other usefu] hydrocarbons, $\mathrm{NH}_{3}$, etr.

The detailed "how to" of hydrogen utilization is beyond the scope of this report and we concentrate solely on the thermochemistry of the basic fuel production process.

The physics data are supportive to the study and are based on the most recent plasma theory and experiment. The model used is that of the tandem minor reactor with thermal barriers.

C.E. Witherel], "Micro-Brazing with Lasers," Lass Focus 17, 11 (1981), pp. 73-80.

Precision metal components are usually joined by melting a filler metal to at least $425^{\circ} \mathrm{C}$. A laser can produce such temperatures without the ruinous side-effects of conventional methods.

C.E. Witherell, Welding Pouder Mctallizrgy Parts, Lawrence Livermore National Laboratory, Livermore, CA, UCRL-87090 (1982). Prepared for the Imterhational fournal of Powder Metallurgy and Pownder Technology.

\footnotetext{
"University of Washington, Nuclear Engineering Department. Suttle, WA 98195

'Gencral Atnmic Company. P.O. Box 81608, San Diego, CA 92138.

"U.C. Davis, Department of Merhanical Engineering. Davis, CA 95616 ,

"Rowe and Associates, 14400 Bellevue Redmond Rd., Suite 208, Bellevue, WA 98195
} 
Welding offers a means for the $\mathrm{P} / \mathrm{M}$ fabricator to increase markets for his product through broadening the range of attainable shapes, sizes, and alloy combinations, But becalre of the porosity and heterogeneity characteristic of most P/M structural parts, welding methods commonly used for mill prosucts and castings are often unsuitable. New techniques have been perfected in recent years for joining difficult-to-weld materials and combinations-many of the techniques being spinoffs from energy and aerospace research. A number of these procedures are plausible candidates for relieving the joining problems that have long plagued the $\mathrm{P} / \mathrm{M}$ industry.
Edward M. Wu, Estimation of Long-Term Life of Polymeric Composites, Lawsence Livermore National Laboratory, Livermore, CA, UCRL-86933 (1981). Prepared for the Soc. of Experimental Stress Analysis//apan's Soc. of Mechanical Engineers 1982 Joint Conf on Experimental Mechanics, Honolulu, HI, May 27-30, 1982.

Estimation or prediction of long term life is crucial to the application of composites in high reliability requirements. In the absence of long term data, short term life under higher stress conditions may be extrapolated to long lem life under lower service stress conditions. We present an extrapolation method which improves the acedracy of estimation by identifying and maintaining the same failure mechanism in all the time ranges. 